\title{
The effects of atmospheric waves on the amounts of polar stratospheric clouds
}

\author{
M. Kohma and K. Sato \\ Department of Earth and Planetary Science, The University of Tokyo, Tokyo, Japan
}

Received: 27 May 2011 - Published in Atmos. Chem. Phys. Discuss.: 20 June 2011

Revised: 11 November 2011 - Accepted: 11 November 2011 - Published: 21 November 2011

\begin{abstract}
A quantitative analysis on the relationship between atmospheric waves and polar stratospheric clouds (PSCs) in the 2008 austral winter and the 2007/2008 boreal winter is made using CALIPSO, COSMIC and Aura MLS observation data and reanalysis data. A longitude-time section of the frequency of PSC occurrence in the Southern Hemisphere indicates that PSC frequency is not regionally uniform and that high PSC frequency regions propagate eastward at different speeds from the background zonal wind. These features suggest a significant influence of atmospheric waves on PSC behavior. Next, three temperature thresholds for PSC existence are calculated using $\mathrm{HNO}_{3}$ and $\mathrm{H}_{2} \mathrm{O}$ mixing ratios. Among the three, the $T_{\mathrm{STS}}$ (a threshold for super cooled ternary solution)-based estimates of PSC frequency accord best with the observations in terms of the amount, spatial and temporal variation, in particular, for the latitude ranges of $55^{\circ} \mathrm{S}-70^{\circ} \mathrm{S}$ and $55^{\circ} \mathrm{N}-85^{\circ} \mathrm{N}$. Moreover, the effects of planetary waves, synoptic-scale waves and gravity waves on PSC areal extent are separately examined using the $T_{\mathrm{STS}}$-based PSC estimates. The latitude range of $55^{\circ} \mathrm{S}-70^{\circ} \mathrm{S}$ is analyzed because the $T_{\mathrm{STS}}$-based estimates are not consistent with observations at higher latitudes $\left(<75^{\circ} \mathrm{S}\right)$ above $18 \mathrm{~km}$, and PSCs in lower latitudes are more important to the ozone depletion because of the earlier arrival of solar radiation in spring. It is shown that nearly $100 \%$ of PSCs between $55^{\circ} \mathrm{S}$ and $70^{\circ} \mathrm{S}$ at altitudes of $16-24 \mathrm{~km}$ are formed by temperature modulation, which is influenced by planetary waves during winter. Although the effects of synopticscale waves on PSCs are limited, around an altitude of $12 \mathrm{~km}$ more than $60 \%$ of the total PSC areal extent is formed by synoptic-scale waves. The effects of gravity waves on PSC areal extent are not large in the latitude range of $55^{\circ} \mathrm{S}-70^{\circ} \mathrm{S}$. However, at higher latitudes, gravity waves act to increase
\end{abstract}

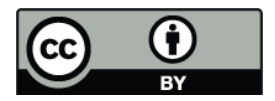

Correspondence to: M. Kohma (kohmasa@eps.s.u-tokyo.ac.jp)
PSC areal extent at an altitude of $15 \mathrm{~km}$ by about $30 \%$ in September. Similar analyses are performed for the Northern Hemisphere. It is shown that almost all PSCs observed in the Northern Hemisphere are attributable to low temperature anomalies associated with planetary waves.

\section{Introduction}

Polar stratospheric clouds (PSCs) are the clouds that appear in the lower stratosphere in polar regions and play two key roles in the catalytic destruction of polar stratospheric ozone (Solomon, 1999). First, PSC particles serve as an environment for heterogeneous reactions that convert inactive chlorine and bromine reservoirs into reactive forms. Second, the uptake of $\mathrm{HNO}_{3}$ into PSC particles and subsequent gravitational sedimentation of the particles remove reactive odd nitrogen $\mathrm{NO}_{\mathrm{y}}$ from the lower stratosphere (denitrification), which extends the lifetime of reactive chlorine significantly.

Although PSCs are observed at high latitudes in both hemispheres, PSCs appear more frequently in the Antarctic than in the Arctic because temperatures in the Antarctic are generally lower than in the Arctic due to weaker planetary wave activity in the Southern Hemisphere. Although PSCs are commonly observed over most of the Antarctic region in austral winter (June to September), the most favorable regions for PSCs are over the Antarctic Peninsula and ice sheets of the East Antarctic (Pitts et al., 2007; Wang et al., 2008). In contrast, PSCs appear sporadically in the Northern Hemisphere winter. In particular, PSC amounts significantly decrease when sudden stratospheric warming occurs. The larger amounts of PSCs in the Antarctic lead to more intense denitrification than in the Arctic. The difference in the PSC climatology and evolution of chemical compositions between the two hemispheres results in asymmetry in stratospheric ozone depletion (Solomon, 1999).

Published by Copernicus Publications on behalf of the European Geosciences Union. 
Since PSCs were first observed more than a century ago (Jørgensen, 2003), a lot of observations of PSCs have been performed based on remote sensing technologies such as ground-based, airborne, satellite solar occultation instruments and satellite lidars. The satellite lidars are superior to the other instruments in the better spatial resolution and globally spatial coverage (Pitts et al., 2007). Previous observational studies have shown the climatology of PSCs in terms of their occurrence at low temperatures, spatial distribution and seasonal variability. Lidar observations showed that PSCs are categorized into three major types: nitric acid tri-hydrate (NAT, Type 1a), super-cooled liquid ternary solution droplets (STS, Type 1b) and water ice (Type 2). PSCs containing high number densities of NAT can act as mother clouds for extremely large NAT particles (so called "NAT rocks") (Fahey et al., 2001; Fueglistaler et al., 2002). These rock particles efficiently remove $\mathrm{HNO}_{3}$ from the lower stratosphere with their large sedimentation velocity (Fahey et al., 2001; Shibata et al., 2003). The NAT formation temperature $\left(T_{\mathrm{NAT}}\right)$ is derived by Hanson and Mauersberger (1988), and although dominant nucleation mechanisms remain uncertain and controversial (Lowe and MacKenzie, 2008), the correlation coefficient between the potential PSC volumes using $T_{\mathrm{NAT}}$ and the Arctic ozone depletion is more than 0.9 (Rex et al., 2004). STS particles which are composed of ternary $\mathrm{HNO}_{3} / \mathrm{H}_{2} \mathrm{SO}_{4} / \mathrm{H}_{2} \mathrm{O}$ particles (Rosen, 1971) are formed by the condensational growth of background stratospheric aerosols. Carslaw et al. (1998) show that these particles are observed in regions where the temperature is lower than $3-4 \mathrm{~K}$ below $T_{\mathrm{NAT}}\left(T_{\mathrm{STS}}\right)$. STS particles do not grow large enough to cause a significant denitrification through their sedimentation. Ice particles can exist at temperatures below frost point $\left(T_{\mathrm{ICE}}\right)$. Previous studies (Tabazadeh et al., 1997; Koop et al., 1998; Carslaw et al., 1999) show by laboratory experiments and observations that ice particles form at temperatures of $2-4 \mathrm{~K}$ below $T_{\mathrm{ICE}}\left(T_{\mathrm{ICE}-\mathrm{nu}}\right)$. In the Antarctic, synoptic-scale temperature fields can be lower than $T_{\text {ICE-nu, }}$ while temperatures in the Arctic are rarely below $T_{\text {ICE-nu, }}$ except for regions where gravity waves are dominant (e.g. Carslaw et al.,1998).

Atmospheric waves such as planetary-scale, synopticscale and gravity waves can cause strong temperature fluctuations in the stratosphere and hence affect PSC amounts and compositions. Teitelbaum and Sadourny (1998) observed PSCs in the Arctic and Antarctic in association with strong planetary-scale uplifts of isentropic surfaces, in which air temperature lowers while mixing ratios of minor constituents are maintained. Also, PSCs and localized ozone minima have been observed in the Arctic, along with the appearance of synoptic-scale anticyclonic potential vorticity anomalies near the tropopause, which cause an uplift of isentropic surfaces in the lower stratosphere (Teitelbaum et al., 2001).

Gravity waves are thought to be responsible for NAT nucleation in the Arctic. Several studies show that ice particles are formed in low temperature anomalies in association with topographically-forced gravity waves (mountain waves) and that NAT PSCs grow through heterogeneous nucleation on the ice (Carslaw et al., 1998). Using models including PSC microphysics and mountain waves, Höpfner et al. (2006) and Eckermann et al. (2009) show that the heterogeneous nucleation of NAT particles on ice caused by mountain waves around the Antarctic Peninsula and Ellsworth Mountains may explain the distribution of NAT particles observed by the Michelson Interferometer for Passive Atmospheric Sounding (MIPAS). Using Challenging Mini-Satellite Payload (CHAMP) radio occultation observations, McDonald et al. (2009) show that gravity waves increase the frequency of temperatures below $T_{\mathrm{NAT}}$ in June in the Antarctic, in particular around the Antarctic Peninsula, which is known as a mountain wave "hotspot". Shibata et al. (2003) pointed out that non-orographic gravity waves generated by spontaneous adjustment which is related to synoptic-scale wave breaking also have an impact on the formation of ice particles. This result indicates that the impact of gravity waves is not restricted to above high mountains.

Several studies show the relationship between air parcel history and PSCs (e.g. Eckermann et al., 2009). However, as mentioned above, Rex et al. (2004) showed a clear linear relationship between Arctic ozone depletion and PSC volume, defined as volumes where local temperature is below $T_{\text {NAT }}$. Rex et al. (2002) also showed that areas where temperatures are lower than $T_{\mathrm{NAT}}$ closely reproduce the heights and times for which PSC were observed by Polar Ozone Aerosol and Monitoring (POAM III) and a ground-based lidar in the Arctic. Pitts et al. $(2007,2009)$ confirmed that PSC estimations based on these temperature thresholds accord well with the observations by Cloud-Aerosol Lidar and Infrared Pathfinder Satellite Observations (CALIPSO) in both Antarctic and Arctic winters.

For a better understanding of stratospheric ozone destruction in association with PSCs, a quantitative analysis on the relationship between atmospheric waves and PSCs is needed. For this purpose, we examine four kinds of observation data: PSC data from CALIPSO, $\mathrm{H}_{2} \mathrm{O}$ and $\mathrm{HNO}_{3}$ data from a satellite microwave limb sounder (Aura MLS; EOS Microwave Limb Sounder on Aura spacecraft), reanalysis data (ERAInterim; ECMWF Re-Analysis Interim) and high-resolution dry temperature data from GPS radio occultation observations (COSMIC/FORMOSAT-3; Constellation Observing System for Meteorology Ionosphere and Climate/Formosa Satellite Mission-3). Although an analysis is made of the three winters of 2007, 2008 and 2009 in the Antarctic and of the two winter periods of 2007/2008 and 2008/2009 in the Arctic in this study, only the results for typical time periods of June through September 2008 in the Antarctic and of December 2007 through February 2008 in the Arctic are shown. The ozone hole area, defined as the region with total column ozone below 220 Dobson Units to the south of $40^{\circ} \mathrm{S}$, in the austral winter of 2008 is largest among these three austral winters. PSCs are scarcely observed in the boreal winter 
of 2008/2009 because stratospheric warming occured in January 2009.

A detailed description of the data used in this study can be found in Sect. 2. Characteristics of PSCs observed by CALIPSO satellite are described, and the validity of estimations of PSC amounts based on temperature thresholds are shown in Sect. 3. Section 4 shows the dynamical mechanism of low temperatures caused by atmospheric waves. The effects of atmospheric waves on PSC amounts in the Southern and Northern Hemispheres are quantitatively examined in Sects. 5 and 6, respectively. The summary and concluding remarks are given in Sect. 7.

\section{Data description}

\subsection{CALIPSO data}

CALIPSO's payload consists of the Cloud-Aerosol Lidar with Orthogonal Polarization (CALIOP), the Wide Field Camera and the Imaging Infrared Radiometer (Pitts et al., 2007). In this study, the CALIOP Level 2 Vertical Feature Mask (VFM) data product (version 3.01) is used to examine PSCs. CALIPSO is operated in a $98^{\circ}$ inclination orbit and provides measurements extending to the highest latitude of $82^{\circ}$. CALIOP is suitable for the observation of PSCs because of its high vertical and horizontal resolutions and its high sensitivity to optically thin clouds. The data product describes the vertical profiles of cloud and aerosol layers along the track of CALIPSO. Vertical (horizontal) resolutions are $60 \mathrm{~m}(1000 \mathrm{~m})$ in the altitude range of $8.2-20.2 \mathrm{~km}$ and $180 \mathrm{~m}$ $(1667 \mathrm{~m})$ in the altitude range of $20.2-30.2 \mathrm{~km}$. In this data product, cloud and aerosol layers are categorized into feature types. One type, "stratospheric", includes the cloud and aerosol layers with bases above the tropopause, which is determined from static stability in the Global Modeling and Assimilation Office (GMAO) Goddard Earth Observing System Model Version 5 (GEOS-5) meteorological data set, following the definition of World Meteorology Organization. However, because there is usually a weak minimum in the temperature profile at around an altitude of $25 \mathrm{~km}$ in the polar night region in winter, determining tropopause from static stability is occasionally inaccurate. Thus, in some cases, PSCs are categorized as "clouds" in the troposphere. To avoid this problem, both "stratospheric" and "cloud" feature types above an altitude of $11 \mathrm{~km}$ are classified as PSCs in this study. So as to make the data size smaller, the CALIOP data, with an original vertical resolution of $60 \mathrm{~m}$ at altitudes of $8.2-20.2 \mathrm{~km}$, are averaged every $180 \mathrm{~m}$, making the same resolution as for $20.2-30.2 \mathrm{~km}$.

CALIOP transmits laser light simultaneously at $532 \mathrm{~nm}$ and $1064 \mathrm{~nm}$ at a pulse radiation rate of $20.16 \mathrm{~Hz}$, and measures the backscatter intensity at $1064 \mathrm{~nm}$ and two orthogonally polarized components at $532 \mathrm{~nm}$. Although PSC type classification can be performed using these data (Noel et al.,
2008; Pitts et al., 2009), this study mainly examines PSCs in terms of spatial and temporal variations.

\subsection{ERA-Interim data}

To analyze the temperature fields containing atmospheric waves with horizontal scales larger than synoptic-scales (about several-hundred km), ERA-Interim data (Dee et al., 2011) are used. The horizontal resolution of the ERAInterim data is $1.5^{\circ} \times 1.5^{\circ}$, and the temporal interval is $6 \mathrm{~h}$. Daily-averaged data at 14 vertical levels between $300 \mathrm{hPa}$ and $10 \mathrm{hPa}$ are used in this study. Although the vertical grid points of ERA-Interim data are originally archived in terms of pressure, the data are linearly interpolated at a geopotential-height interval of $100 \mathrm{~m}$ to make comparison with CALIPSO observations easier. Wind data are also used to calculate the potential vorticity on isentropic surfaces.

Figures $1 \mathrm{a}$ and $1 \mathrm{~b}$ show the time-altitude sections of zonalmean zonal wind $\bar{U}$ and zonal-mean temperature $\bar{T}$ averaged over a latitude region of $55^{\circ} \mathrm{S}-85^{\circ} \mathrm{S}$ for the time period May through October, 2008. In June through September, strong westerly winds $\left(>40 \mathrm{~m} \mathrm{~s}^{-1}\right)$ occur above $25 \mathrm{~km}$. Temperature is quite low $(\sim 192 \mathrm{~K})$ in the altitude range of $18-27 \mathrm{~km}$ in late June through August. In late August, the altitude region where $\bar{T}$ is lower than $192 \mathrm{~K}$ gradually disappears. It is worth noting that a rapid rise in temperature $(\sim 2 \mathrm{~K})$ is observed during 6-7 August. Figure 1c and d are the same as Fig. 1a and b but are averaged over the latitude range of $55^{\circ} \mathrm{N}-85^{\circ} \mathrm{N}$ from November 2007 through March 2008. Increasingly rapid temperature rises are observed with higher altitudes. In particular, after 22 February, temperature rises extend down to altitudes of about $10 \mathrm{~km}$, and zonal winds become easterly in the latitude range of $70^{\circ} \mathrm{S}-85^{\circ} \mathrm{S}$.

\subsection{COSMIC/FORMOSAT-3 data}

In order to analyze gravity waves, dry temperature data from GPS occultation measurements by COSMIC/FORMOSAT-3 (hereafter referred to as COSMIC) are used. The dry temperature profiles are calculated from observed refractivity under the assumption that water vapor pressure and electron density are negligible. According to Schreiner et al. (2007) and Shepherd and Tsuda (2008), the accuracy of dry temperature observations at the altitudes between $10 \mathrm{~km}$ and $30 \mathrm{~km}$ is better than $0.5 \mathrm{~K}$. Although the nominal vertical resolution of the temperature profiles is about $0.1 \mathrm{~km}$, the effective vertical resolution is about $1 \mathrm{~km}$ in the upper troposphere and stratosphere (Shepherd and Tsuda, 2008). Note that GPS radio occultation observations including COSMIC have been used in the data assimilation process for ERA-Interim since 2006. The bias between the two is less than $0.5 \mathrm{~K}$, which is negligible for PSC analysis in this study. See Anthes et al. (2008) for more details of COSMIC. 

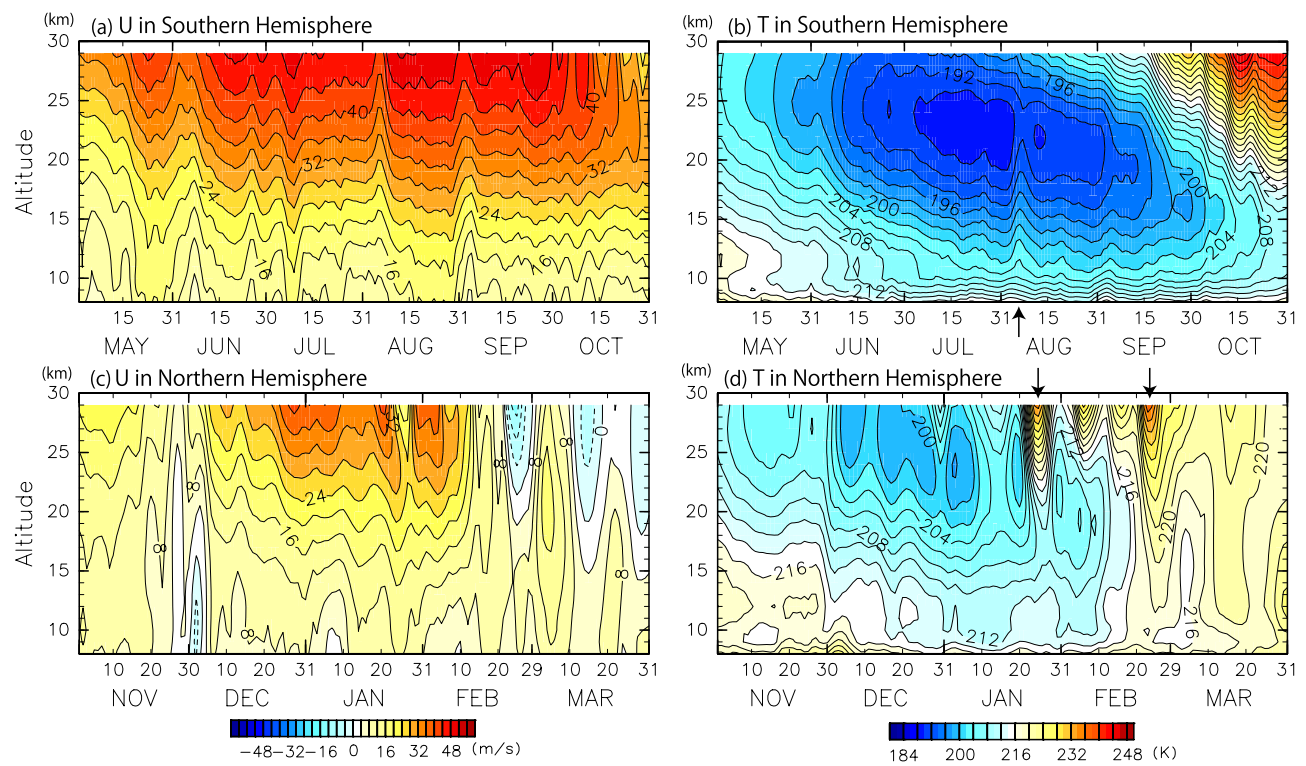

Fig. 1. Time-altitude sections of (a) $\bar{U}$ and (b) $\bar{T}$ averaged within the latitude range of $55^{\circ} \mathrm{S}-85^{\circ} \mathrm{S}$ in May through October 2008 and (c) $\bar{U}$ and (d) $\bar{T}$ within the latitude range of $55^{\circ} \mathrm{N}-85^{\circ} \mathrm{N}$ in November 2007 through March 2008 . Arrows on the bottom of (b) and on the top of (d) show timings when warmings occur.

\subsection{Aura MLS data}

In order to estimate the temperature thresholds for PSCs as accurately as possible, the observation data of $\mathrm{HNO}_{3}$ and $\mathrm{H}_{2} \mathrm{O}$ from MLS on the Aura satellite (version 2.2) are used. Detailed discussions on validity of $\mathrm{HNO}_{3}$ and $\mathrm{H}_{2} \mathrm{O}$ data from Aura MLS are found in Santee et al. (2007) and Lambert et al. (2007), respectively. The along-track and vertical resolutions are respectively several-hundred $\mathrm{km}$ and several $\mathrm{km}$ in the lower stratosphere. As a part of the A-Train satellite constellation, Aura satellite and CALIPSO follow almost the same orbit.

\subsection{Estimation method of PSC using temperature thresholds}

A temperature threshold for Type 1a PSC ( $T_{\mathrm{NAT}}$; Hanson and Mauersberger, 1988) is estimated based on the MLS observations. Following Carslaw et al. (1994), STS formation temperature ( $\left.T_{\mathrm{STS}}\right)$ is assumed to be $3.5 \mathrm{~K}$ below $T_{\mathrm{NAT}}$. The ice frost point temperature $\left(T_{\mathrm{ICE}}\right)$ is calculated using the formulae derived by Marti and Mauersberger (1993). Previous studies show that ice particles are formed at temperatures which are $2-4 \mathrm{~K}$ lower than $T_{\mathrm{ICE}}$ (Tabazadeh et al., 1997; Koop et al., 1998). In this study, the temperature threshold for Type II PSCs ( $T_{\text {ICE-nu }}$ ) is defined as the temperature that is $3 \mathrm{~K}$ below $T_{\text {ICE }} . T_{\text {STS }}$ and $T_{\text {ICE-nu }}$ are derived at each grid point using the same methodology as for $T_{\mathrm{NAT}}$. Note that $T_{\mathrm{NAT}}$ and $T_{\mathrm{STS}}$ are functions of the mixing ratios of $\mathrm{HNO}_{3}$ and $\mathrm{H}_{2} \mathrm{O}$ and atmospheric pressure, while $T_{\text {ICE-nu }}$ is a function of the $\mathrm{H}_{2} \mathrm{O}$ mixing ratio and pressure. Note that the di- agnostic estimation of PSCs using these temperature thresholds ignores the detailed microphysics and sedimentation of various particles.

In previous studies, the spatial and temporal variations of the mixing ratios of $\mathrm{HNO}_{3}$ and/or $\mathrm{H}_{2} \mathrm{O}$ have often been ignored (i.e. $\mathrm{HNO}_{3}$ and/or $\mathrm{H}_{2} \mathrm{O}$ is assumed to be constant) for calculating the temperature thresholds. However, uptake of $\mathrm{HNO}_{3}$ and $\mathrm{H}_{2} \mathrm{O}$ into PSC particles decreases the mixing ratios of $\mathrm{HNO}_{3}$ and $\mathrm{H}_{2} \mathrm{O}$ in the lower stratosphere, and consequently the temperature thresholds become lower in middle and late winter than in early winter. To include these variations in our quantitative analyses, the observed mixing ratios of $\mathrm{HNO}_{3}$ and $\mathrm{H}_{2} \mathrm{O}$ are averaged within $20^{\circ} \times 5^{\circ}$ longitudelatitude grid boxes and over one day at each level. Then, they are interpolated linearly into the same horizontal grids as those of the reanalysis data. A linear vertical log-pressure interpolation into the same pressure levels as those of the reanalysis is also performed. Using these rearranged $\mathrm{HNO}_{3}$ and $\mathrm{H}_{2} \mathrm{O}$ data, $T_{\mathrm{NAT}}, T_{\mathrm{STS}}$ and $T_{\mathrm{ICE}-\mathrm{nu}}$ are obtained at each grid point.

It is worth noting that lower mixing ratios of $\mathrm{HNO}_{3}$ and $\mathrm{H}_{2} \mathrm{O}$ caused by denitrification and dehydration are difficult to detect, and the values that are observed may not be accurate. In austral winter, in particular in July and August, there are negative values in the $\mathrm{HNO}_{3}$ observation data around an altitude of $22 \mathrm{~km}$ (Santee et al., 2007). In calculation of temperature thresholds in the present study, these negative mixing ratios are not included. 


\section{PSC frequency observed by CALIPSO and estimates by temperature thresholds}

The frequency of PSC occurrence $F$, hereinafter referred to as PSC frequency, is obtained using CALIPSO observation data for each day at vertical intervals of $1 \mathrm{~km}$ within $20^{\circ} \times 5^{\circ}$ longitude-latitude grid boxes. PSC frequency is defined as the ratio of the number of cases where PSCs were detected to the total number of observations. The size of grid boxes is chosen so that more than $90 \%$ of grid boxes in the latitude range of $60^{\circ} \mathrm{S}-80^{\circ} \mathrm{S}$ contain at least 10 observations. The total number of observations is usually about 160 for each grid box.

Figure 2 shows latitude-altitude sections of zonal-mean monthly-mean PSC frequency in the time period of June through September 2008. More than 99\% of PSCs in the Southern Hemisphere are observed in the latitude and altitude region of $55^{\circ} \mathrm{S}-85^{\circ} \mathrm{S}$ and $11-30 \mathrm{~km}$. This region is the focus of the following analyses in the Southern Hemisphere, and therefore constitutes the major component of this paper.

Figure 3a shows a longitude-time section of PSC frequency averaged within the range of $65^{\circ} \mathrm{S}-70^{\circ} \mathrm{S}$ and 18 $20 \mathrm{~km}$ in the time period from June through September 2008. The altitude range of $18-20 \mathrm{~km}$ was chosen because PSCs are frequently observed there (see Fig. 2). Note that data during 3-11 June, 18-22 July, 8-10 September and 26-30 September are missing. PSC frequency increases in June and decreases in September. Although it is clear that PSCs are observed in most longitudes, they appear most frequently in the longitude range $0^{\circ}-90^{\circ} \mathrm{W}$ in June and September, which is consistent with previous studies using CALIPSO observations (Pitts et al., 2007; McDonald et al., 2009). It is interesting to note that high $F$ regions propagate eastward, which accords well with the movement of low temperature anomalies. The propagation speeds of high $F$ regions are concentrated around $20 \mathrm{~m} \mathrm{~s}^{-1}$, as shown by a solid arrow in Fig. 3a. This is slower than the zonal-mean zonal wind (about $35 \mathrm{~m} \mathrm{~s}^{-1}$ ) at this level (a dashed arrow). Similar patterns of propagation and regional dependence for PSC frequency are also observed in the austral winters of 2007 and 2009 (not shown). These facts suggest that the eastward propagation of high $F$ regions is not simply due to advection of PSCs by background wind but due to modulation by atmospheric waves.

The propagations of high $F$ region with propagation speed of $20 \mathrm{~m} \mathrm{~s}^{-1}$ are mainly observed in June through July and associated with the movement of wavenumber- 2 structure of temperature anomaly (contours in Fig. 3b-d). More slowly eastward propagating $F$ patterns are observed in early August and early September, in association with the zonal wavenumber-1 structure of temperature.

The most frequently-used proxy to estimate PSC areal extent is the area where $T \leq T_{\mathrm{NAT}}$ (e.g. Rex et al., 1999, 2004). The $T_{\mathrm{NAT}}$-based PSC frequency is calculated within $20^{\circ} \times 5^{\circ}$ longitude-latitude grid boxes at the altitudes of $18-20 \mathrm{~km}$ for each day using temperature from ERA-Interim data and

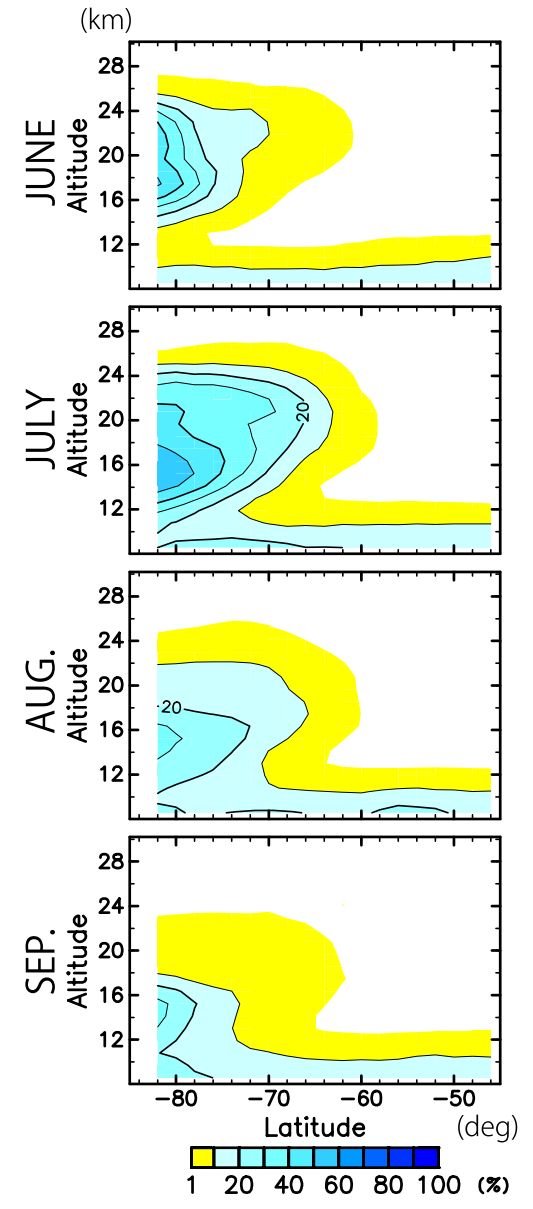

Fig. 2. Latitude-altitude sections of zonal-mean monthly-mean PSC frequency $F$, in June through September 2008, obtained from CALIPSO data.

$\mathrm{HNO}_{3}$ and $\mathrm{H}_{2} \mathrm{O}$ mixing ratios from Aura MLS. The $T_{\mathrm{NAT}}-$ based PSC frequency for each grid box is defined as the ratio of the number of grid points with $T<\mathrm{T}_{\mathrm{NAT}}$ to the total number of grid points. Similarly, PSC frequencies are calculated also based on $T_{\mathrm{STS}}$ and $T_{\text {ICE-nu. }}$.

Figure $3 \mathrm{~b}-\mathrm{d}$ show the longitude-time sections of PSC frequencies averaged for the latitude range of $65^{\circ} \mathrm{S}-70^{\circ} \mathrm{S}$ and $18-20 \mathrm{~km}$ based on $T_{\mathrm{NAT}}, T_{\mathrm{STS}}$, and $T_{\mathrm{ICE}-\mathrm{nu}}$, respectively. It is clear that $T_{\mathrm{STS}}$-based PSC frequency estimates accord best among the three with observations by CALIPSO (Fig. 3a) in terms of magnitudes of PSC frequency and eastward propagation speeds. On the other hand, the $T_{\mathrm{NAT}}$-based estimates are much larger than observations. Reflecting the fact that

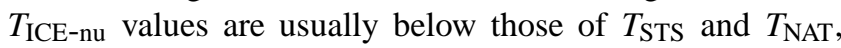

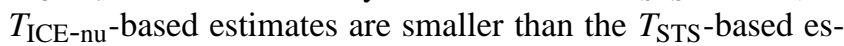
timates. It is worth noting that while $T_{\mathrm{STS}}$-based PSC frequencies greater than $10 \%$ are observed in regions where $T<194 \mathrm{~K}$ in June, they are also observed in regions where $T<192 \mathrm{~K}$ in late August. This is likely because $T_{\mathrm{STS}}$ decreases due to a reduction in $\mathrm{HNO}_{3}$ and $\mathrm{H}_{2} \mathrm{O}$ mixing ratios from their uptake into PSC particles. 

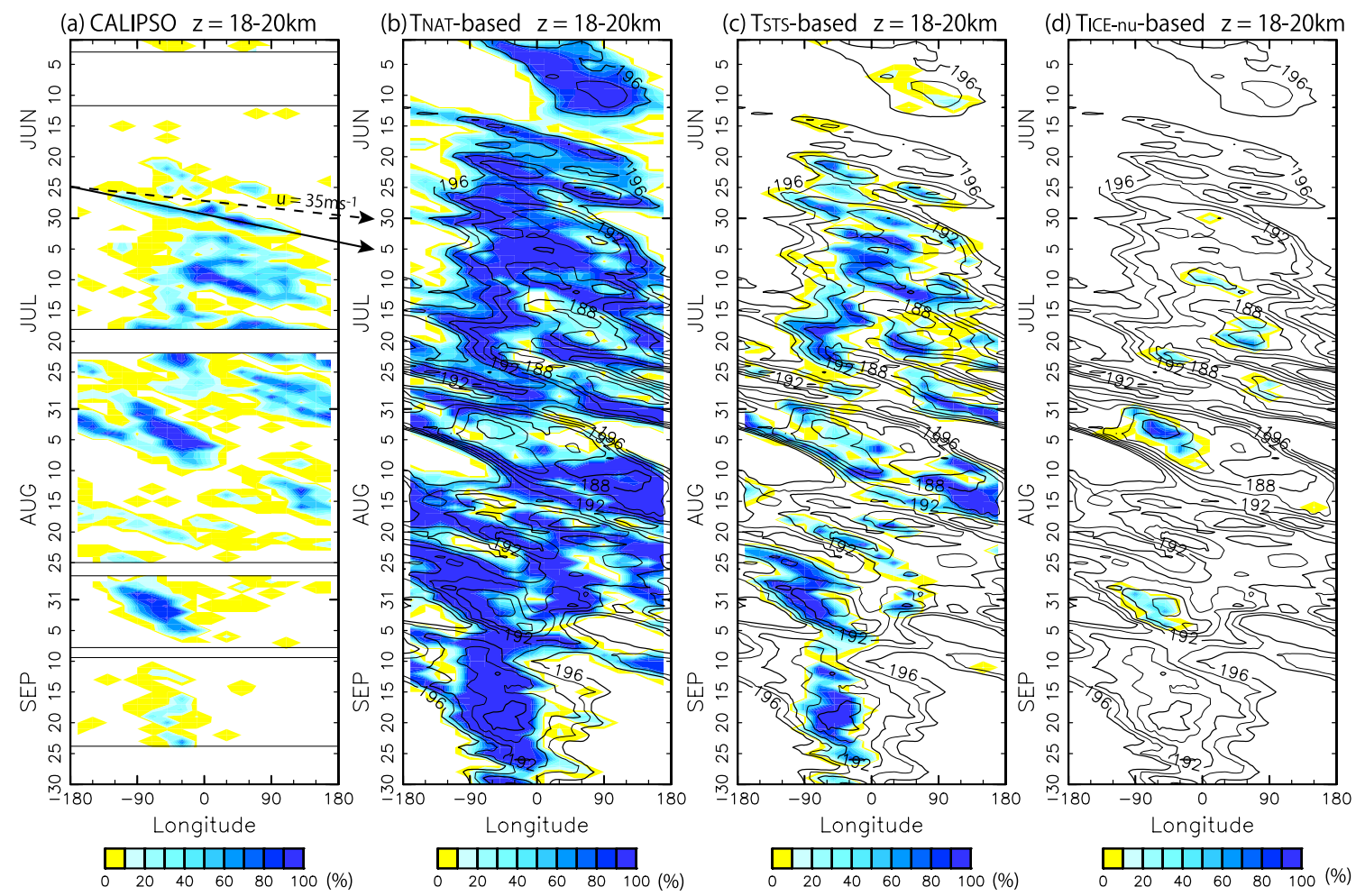

Fig. 3. (a) Hovmöller diagram of PSC frequency from CALIPSO observations in austral winter of 2008 averaged within an altitude range of $18-20 \mathrm{~km}$ in the latitude range of $65^{\circ} \mathrm{S}-70^{\circ} \mathrm{S}$. Time periods surrounded by black solid lines denote time periods when CALIPSO data are missing. A solid arrow shows the zonal velocity $\left(20 \mathrm{~m} \mathrm{~s}^{-1}\right)$ of high $F$ regions. A dashed arrow shows zonal-mean zonal wind speed $\left(35 \mathrm{~m} \mathrm{~s}^{-1}\right)$. (b) The same as (a) but for the $F$ estimates based on $T_{\mathrm{NAT}}$ as a temperature threshold. Contour lines show temperatures at $50 \mathrm{hPa}$ from ERA-Interim data at an interval of $2 \mathrm{~K}$. (c) and (d) The same as (b) but for $T_{\mathrm{STS}}$ and $T_{\mathrm{ICE}-\mathrm{nu}}$ as temperature thresholds, respectively.

Figure 4 shows results for a higher latitude range of $75^{\circ} \mathrm{S}-$ $80^{\circ} \mathrm{S}$. PSC frequency observed by CALIPSO is higher at higher latitudes. However, $T_{\mathrm{STS}}$-based estimates do not match the observations, in particular, in low temperature $(T<184 \mathrm{~K})$ regions in July and August. It is likely that severe denitrification and dehydration during this time period cause extremely large reductions of $\mathrm{HNO}_{3}$ and $\mathrm{H}_{2} \mathrm{O}$ mixing ratios, meaning that they are too small to be detected by MLS measurements. In addition, as Pitts et al. (2007) point out, the temperature thresholds $T_{\mathrm{NAT}}, T_{\mathrm{STS}}$ and $T_{\mathrm{ICE}}$ will be underestimated if they are not calculated using "total" $\mathrm{HNO}_{3}$ and $\mathrm{H}_{2} \mathrm{O}$ mixing ratios, i.e. gas phase mixing ratios plus those of $\mathrm{HNO}_{3}$ and $\mathrm{H}_{2} \mathrm{O}$ which have been taken up into the PSC particles. Thus, the values of $T_{\mathrm{STS}}$ can be underestimated in regions where PSC amounts are large. Optically thin PSCs may not be detectable by CALIOP (Pitts et al., 2007). It should be also noted that the estimated PSCs based on temperature thresholds ignore detailed cloud microphysics (e.g. the rate of formation and evaporation of PSC particles differ) and sedimentation of particles (Sect. 2.5).

Based on the above results, it is inferred that the $T_{\mathrm{STS}}{ }^{-}$ based PSC frequency estimate are more reliable at low latitudes $\left(<70^{\circ} \mathrm{S}\right)$ in the Antarctic. Thus, in the following sec- tions, our analysis will focus on PSCs mainly in the lower latitudes using $T_{\text {STS }}$-based PSC frequency estimates. It should also be emphasized that PSCs in lower latitudes are more important to ozone depletion because of the earlier arrival of solar radiation in spring. In addition, even at latitudes higher than $70^{\circ} \mathrm{S}$, temperatures at altitudes of $12-15 \mathrm{~km}$ are not low enough to cause strong denitrification and dehydration. Thus, $T_{\mathrm{STS}}$-based estimates become accurate at latitudes higher than $70^{\circ} \mathrm{S}$ and between 12 and $15 \mathrm{~km}$.

\section{Temperature fluctuation caused by atmospheric waves in the lower stratosphere}

\subsection{Planetary and synoptic-scale waves}

As shown in Sect. 3, the eastward propagation of high-PSCfrequency regions accords well with low temperature anomalies which are likely associated with atmospheric waves. In this section, we discuss how planetary and synoptic-scale waves cause low temperature anomalies. An analysis was made of the potential vorticity (PV) because these waves are essentially PV fluctuations: PV is defined as follows: 

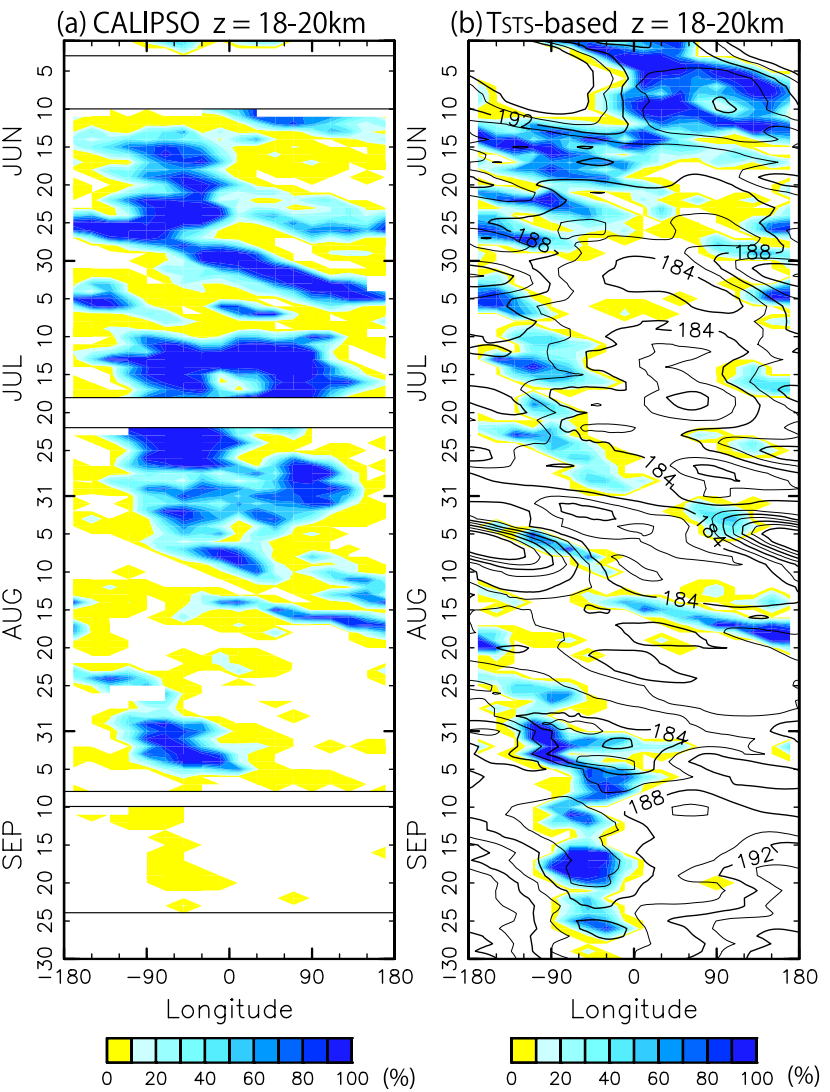

Fig. 4. The same as Fig. 3a and c but for the latitude range of $75^{\circ} \mathrm{S}-$ $80^{\circ} \mathrm{S}$.

$\mathrm{PV}=\frac{\zeta+f}{\sigma}$,

where $\sigma^{-1}=-g \frac{\partial \theta}{\partial p}$ is thickness, $\zeta$ is relative vorticity, $f$ is planetary vorticity, $\theta$ is potential temperature and $g$ is gravity acceleration. Potential vorticities on the $300 \mathrm{~K}(500 \mathrm{~K})$ isentropic surface, corresponding to an altitude of about $8 \mathrm{~km}$ $(20 \mathrm{~km})$, in the polar winter are analyzed to examine the behaviors of mainly synoptic-scale waves (planetary waves). In this study, planetary waves are defined as disturbances having zonal wavenumbers $(s)$ of 1-3 ( $s=1-3$ components) and synoptic-scale waves as $s=4-20$ components.

Planetary waves can cause a positive correlation between $\mathrm{PV}$ and temperature anomalies in the middle stratosphere of the Southern Hemisphere. Figure 5a shows a scatter diagram of $s=1-3$ potential vorticity components on the $500 \mathrm{~K}$ isentropic surface and $s=0-3$ temperature components at $50 \mathrm{hPa}$ (near an altitude of $20 \mathrm{~km}$ ) for $65^{\circ} \mathrm{S}-70^{\circ} \mathrm{S}$ in July, 2008. Note that the negative (positive) PV anomalies correspond to cyclonic (anticyclonic) disturbances in the Southern Hemisphere. A strong positive correlation, with a correlation coefficient of 0.771 , is seen between the PV and temperature components. The amplitude of temperature fluctuations associated with planetary waves is about $10 \mathrm{~K}$. The mechanism of this positive correlation is illustrated on Fig. 5b. The
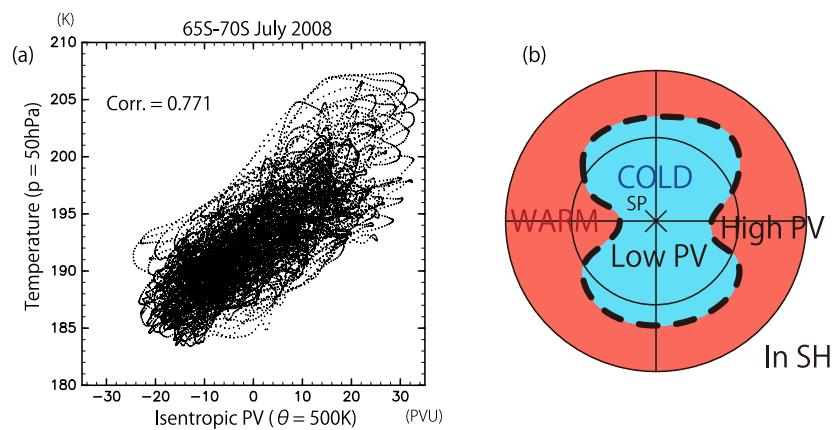

Fig. 5. (a) Scatter diagram of $s=1-3$ potential vorticity fluctuation components on $500 \mathrm{~K}$ isentropic surface and $s=0-3$ temperature components at $50 \mathrm{hPa}$ in the latitude range of $65^{\circ} \mathrm{S}-70^{\circ} \mathrm{S}$ in July. "Corr." stands for correlation efficient. (b) Schematic illustration of the relation between temperature and potential vorticity in the middle stratosphere of the Southern Hemisphere. Red (blue) area indicates warm (cold) temperature. The broken curve illustrates a polar night jet modulated by a planetary wave.

unperturbed PV isolines are usually oriented zonally around the stratospheric polar vortex. The temperature inside (outside) the polar vortex is low (high) mainly due to differential solar radiative heating. Thus, the anticyclonic PV anomaly (positive anomaly in the Southern Hemisphere) of planetary waves is associated with poleward advection of warm air originating from lower latitudes, and vice versa (Fig. 5b).

PV anomalies around the tropopause associated with synoptic-scale waves are generally thin (e.g. Teitelbaum et al., 2001). The temperature anomalies associated with the PV anomalies are illustrated in Fig. 6b. The anticyclonic PV anomaly (positive anomaly in the Southern Hemisphere) accompanies negative temperature anomaly above the tropopause and may cause PSCs. Figure 6a shows a scatter diagram of $s=4-20$ potential vorticity components on the $300 \mathrm{~K}$ isentropic surface $(\sim 8 \mathrm{~km})$ around the tropopause and $s=4-20$ temperature components at $100 \mathrm{hPa}$ $(\sim 15 \mathrm{~km})$ in the lower stratosphere for the latitude range of $65^{\circ} \mathrm{S}-70^{\circ} \mathrm{S}$ in July. PV and temperature components are negatively correlated. Figure $6 \mathrm{c}$ shows a composite of $s=4-20$ temperature components in a longitude-pressure section for July 2008. The reference points are determined where $s=4-20$ isentropic potential vorticity components are positively maximized in the zonal direction at $65^{\circ} \mathrm{S}$ at $\theta=300 \mathrm{~K}$, and with their maximum value larger than 2.5 PVU (PVU $=10^{-6} \mathrm{~m}^{2} \mathrm{~s}^{-1} \mathrm{~K} \mathrm{~kg}^{-1}$ ). The number of cases used for the composite is 21 . The vertical structure of the temperature anomaly is similar to the schematic illustration shown in Fig. 6b. The amplitude of the temperature anomaly at $100 \mathrm{hPa}$ is $1 \mathrm{~K}$, which is consistent with the range of the scatter diagram shown in Fig. $6 \mathrm{a}$. 

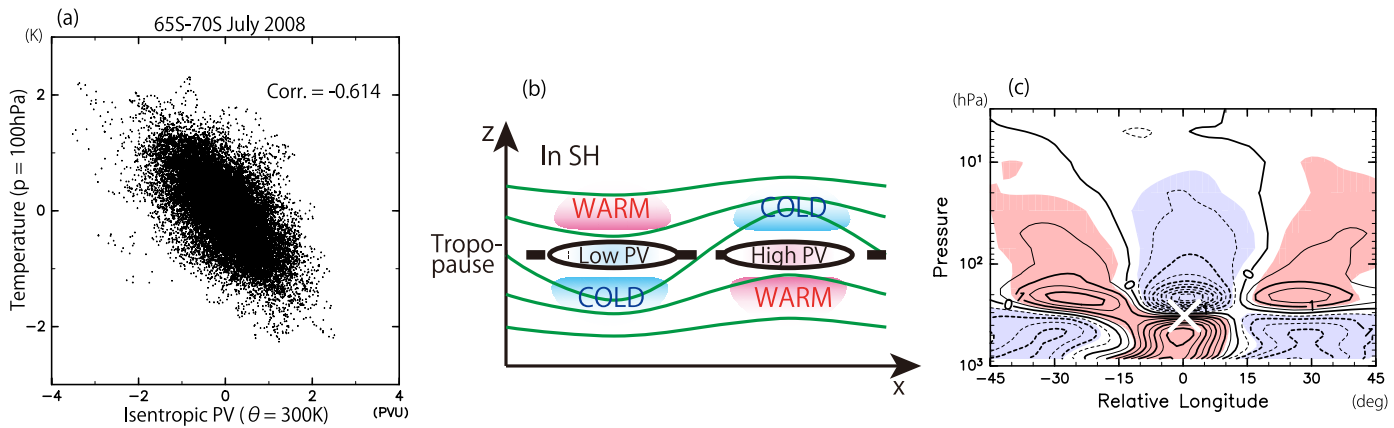

Fig. 6. (a) A scatter diagram of $s=4-20$ potential vorticity fluctuation components on $300 \mathrm{~K}$ isentropic surface and $s=4-20$ temperature fluctuation components at $100 \mathrm{hPa}$ in the latitude range of $65^{\circ} \mathrm{S}-70^{\circ} \mathrm{S}$ in July. "Corr." stands for correlation coefficient. (b) A schematic illustration of the relation between temperature anomalies (colors) and potential vorticity near the tropopause (black broken line) in the Southern Hemisphere. Green curves indicate isobars. (c) A composite of the relative longitude-pressure section of $s=4-20$ temperature components in July 2008 with a reference point (a white cross mark) where the $s=4-20$ potential vorticity components are positive and maximized in the zonal direction at $65^{\circ} \mathrm{S}$ on $\theta=300 \mathrm{~K}$ surface, and values are larger than $2.5 \mathrm{PVU}$. Contour intervals are $0.5 \mathrm{~K}$. Broken contours indicate negative values. Shading shows the regions with significance levels greater than $99 \%$.

\subsection{Gravity waves}

As ERA-Interim data do not have sufficient resolution for the study of gravity waves, dry temperature data from COSMIC observations are used. Previous studies using RO observations choose a relatively long cutoff vertical wavelength for gravity waves, such as $10 \mathrm{~km}$ in McDonald et al. (2009) and $15 \mathrm{~km}$ in Alexander et al. (2011). However, the extracted components by these studies may include contamination from planetary waves and synoptic-scale waves having similar vertical scales. To avoid this, we used a relatively short cut off length of $6 \mathrm{~km}$ for a high pass filter in the vertical to extract gravity waves. A discussion of the effect of different cutoff lengths will be made in Sect. 8 .

An analysis is made of the vertical profiles in a restricted height range of $12-30 \mathrm{~km}$, where PSCs are frequently observed. Note that this restriction is effective to avoid mixing spurious temperature fluctuations due to the tropopause structure into gravity waves. However, this process may cause underestimation of the amplitude of gravity waves near the edge of the vertical profile. It is also important to note that the horizontal resolution of the COSMIC data is about $300-400 \mathrm{~km}$ in the polar region, which means that only gravity waves having horizontal wavelengths longer than 600-800 km can be estimated due to the observational filter (Alexander, 1998). Thus, the results shown by this study give the lower limit of the gravity wave effects on PSCs.

Figure 7a shows profiles of original dry temperature and smoothed dry temperature with a lowpass filter with a cutoff length of $6 \mathrm{~km}$ in the vertical at $82.8^{\circ} \mathrm{W}, 80.3^{\circ} \mathrm{S}$ on $29 \mathrm{Au}-$ gust 2008. A blue solid (broken) line indicates $T_{\mathrm{NAT}}\left(T_{\mathrm{STS}}\right)$. Mean values of mixing ratios of $\mathrm{HNO}_{3}(0.2 \mathrm{ppbv})$ and $\mathrm{H}_{2} \mathrm{O}$ (1.8 ppmv) for $100-30 \mathrm{hPa}$ at this point were used for estimation. Temperature fluctuations with amplitudes of about $5 \mathrm{~K}$ are observed above $12 \mathrm{~km}$. Figure $7 \mathrm{~b}$ shows feature type along a CALIPSO orbit on the same day. A green rectangle indicates the region of the temperature profile shown in Fig. 7a. It is clear from Fig. 7a and b that PSCs are observed at altitudes of $13-16 \mathrm{~km}$ and $18-21 \mathrm{~km}$, where temperature is minimized and lower than $T_{\mathrm{STS}}$ due to gravity waves.

\section{The effects of atmospheric waves on PSCs in the Antarctic winter of 2008}

In this section, the effects of planetary waves, synoptic-scale waves and gravity waves on PSC areal extent are quantitatively examined using $T_{\mathrm{STS}}$-based estimates of PSCs. First of all, the reliability of $T_{\mathrm{STS}}$-based PSC areal extent estimates is confirmed by comparing the estimates with PSC areal extent calculated using CALIPSO observations in the latitude range of $55^{\circ} \mathrm{S}-70^{\circ} \mathrm{S}$, in which $T_{\mathrm{STS}}$-based PSC frequency accords well with observations, as shown in Sect. 3. To calculate CALIPSO-based PSC areal extent, firstly, PSC frequency is obtained as in the previous section but for every $1 \mathrm{~km}$ vertical grid point. Then, PSC areal extent for each grid box is determined as PSC frequency in the grid box multiplied by the box area. Figure 8a shows a time-altitude section of CALIPSObased PSC areal extent for $55^{\circ} \mathrm{S}-70^{\circ} \mathrm{S}$. As shown in Pitts et al. (2007, 2009), PSCs are dominant in the altitude region of about $20-25 \mathrm{~km}$ in early June, and down to $12 \mathrm{~km}$ in late June. In late August and September, PSCs gradually disappear above $20 \mathrm{~km}$, and PSC areal extent becomes smaller. The decrease in PSC areal extent is observed at altitudes of 20-24 km during 6-8 August. It is likely that this decrease is related to an increase in zonal-mean temperature in spring (see Fig. 1b). The high PSC frequency below $12 \mathrm{~km}$ may be related to either PSCs or (real) tropospheric clouds, depending on the seasonal and synoptic-scale meteorological 


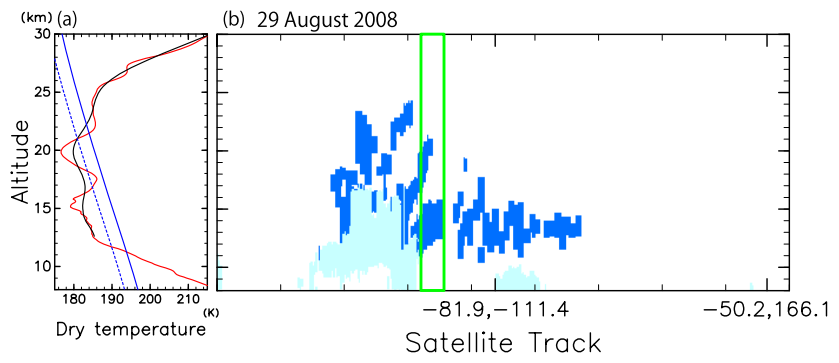

Fig. 7. (a) Original (red) and smoothed (black) profiles of dry temperature at $82.8^{\circ} \mathrm{W}, 80.2^{\circ} \mathrm{E}$ on 29 August 2008 from COSMIC. A smoothing was made using a lowpass filter with a cutoff length of $6 \mathrm{~km}$. A blue solid (broken) line indicates $T_{\mathrm{NAT}}\left(T_{\mathrm{STS}}\right)$. (b) A horizontal and height section of feature type from CALIPSO on 29 August 2008. Blue (light blue) areas indicate "stratospheric" cloud (tropospheric "cloud") layers. A green rectangle indicates the region of the dry temperature profile show in (a).
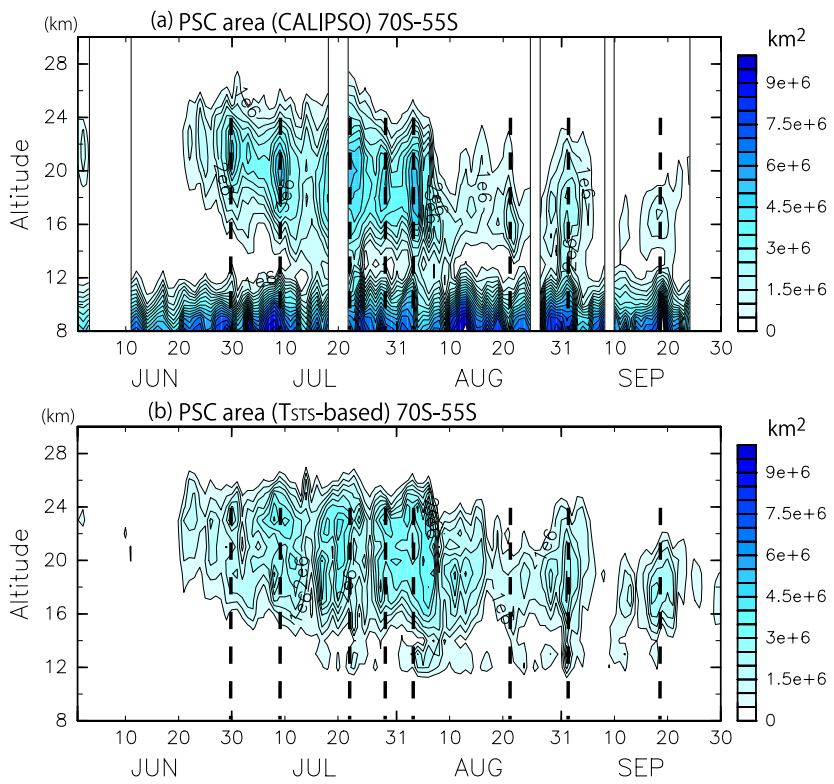

Fig. 8. Time-altitude sections of (a) PSC areal extent obtained from CALIPSO observations and (b) $T_{\mathrm{STS}}$-based PSC areal extent in the latitude range of $55^{\circ} \mathrm{S}-70^{\circ} \mathrm{S}$ in 2008 . Broken lines show timings when observed PSC areal extent is maximized. Thin solid lines show the time periods during which CALIPSO data are missing. Contour intervals are $5 \times 10^{5} \mathrm{~km}^{2}$.

conditions. For this reason, the analysis of the clouds below $12 \mathrm{~km}$ is left for future studies.

$T_{\text {STS }}$-based PSC areal extent is calculated in the same way as CALIPSO-based PSC areal extent. Figure 8b shows a time-altitude section of $T_{\mathrm{STS}}$-based PSC areal extent. It is clear that the $T_{\mathrm{STS}}$-based estimates, in particular, timings and altitudes of $T_{\mathrm{STS}}$-based PSC areal extent maxima (vertical broken lines in Fig. 8), generally accord well with the observations. Upper edges and peaks of $T_{\mathrm{STS}}$-based PSC areal

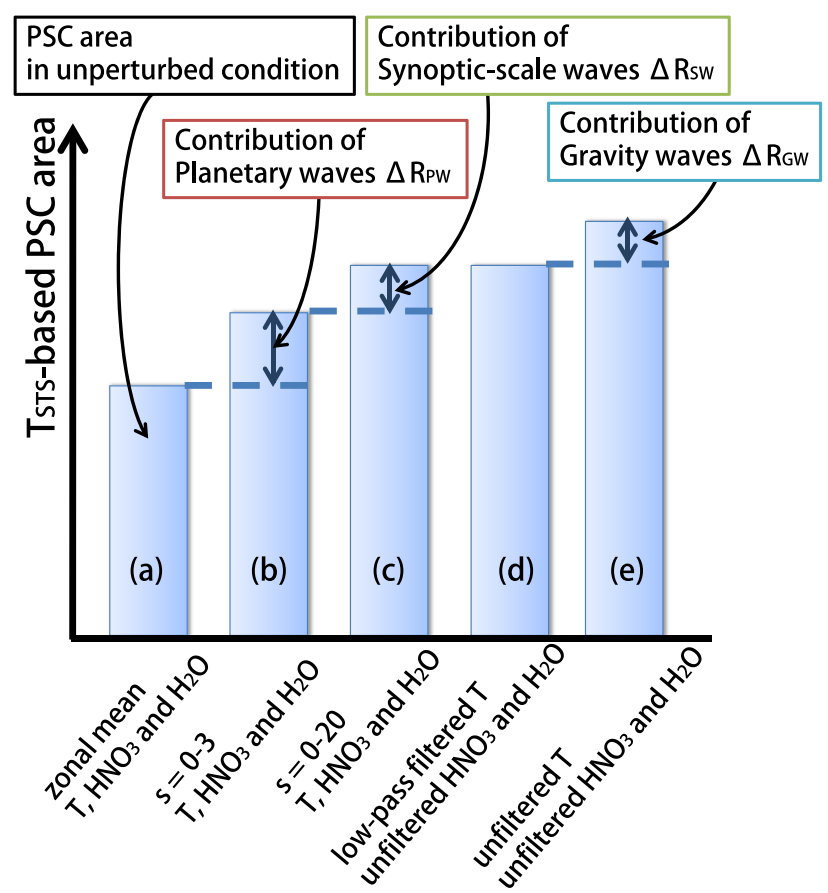

Fig. 9. A method to estimate the effects of planetary waves, synoptic-scale waves and gravity waves on PSC areal extent. (a) $T_{\mathrm{STS}}$-based PSC area calculated from $s=0$ componets (i.e. zonalmean) of temperature from ERA-Interim data and mixing ratios of $\mathrm{HNO}_{3}$ and $\mathrm{H}_{2} \mathrm{O}$ from Aura MLS. (b-c) Same as (a) but for $s=0-3$ and $s=0-20$ components, respectively. (d-e) $T_{\text {STS }}$-based PSC area calculated from smoothed and original temperature from COSMIC, respectively. The cutoff length of the lowpass filter used for temperature in $(\mathbf{d})$ is $6 \mathrm{~km}$. The unfiltered mixing ratios of $\mathrm{HNO}_{3}$ and $\mathrm{H}_{2} \mathrm{O}$ are used.

extent are located slightly higher than those of CALIPSObased PSC, which may reflect on the effect of sedimentation of PSC particles ignored in the present analysis.

To estimate the effects of planetary waves, synoptic-scale waves and gravity waves, PSC areal extents with and without the respective waves are compared. The effects of the respective waves are quantified in terms of PSC coverage ratio $R(z, t)$, defined as the summation of PSC areal extent over all longitudes in the latitude range of $55^{\circ} \mathrm{S}-70^{\circ} \mathrm{S}$ normalized by the analyzed area. In other words, $R(z, t)$ corresponds to the zonal and latitudinal mean of PSC frequency weighted by length of latitude circle. The method of analysis is shown in Fig. 9. PSC coverage ratio with planetary waves is calculated using $s=0-3$ components of ERAInterim temperature, Aura MLS $\mathrm{HNO}_{3}$ and $\mathrm{H}_{2} \mathrm{O}$ mixing ratios (Fig. 9b). The unperturbed PSC coverage ratio is calculated using zonal-mean (i.e. $s=0$ ) temperature, $\mathrm{HNO}_{3}$ and $\mathrm{H}_{2} \mathrm{O}$ data (Fig. 9a). Then, the difference between the two PSC coverage ratios $\Delta R_{\mathrm{PW}}$, is obtained as the effect of planetary waves. A positive $\Delta R_{\mathrm{PW}}$ value means that planetary waves increase $R(z, t)$, and vice versa. 

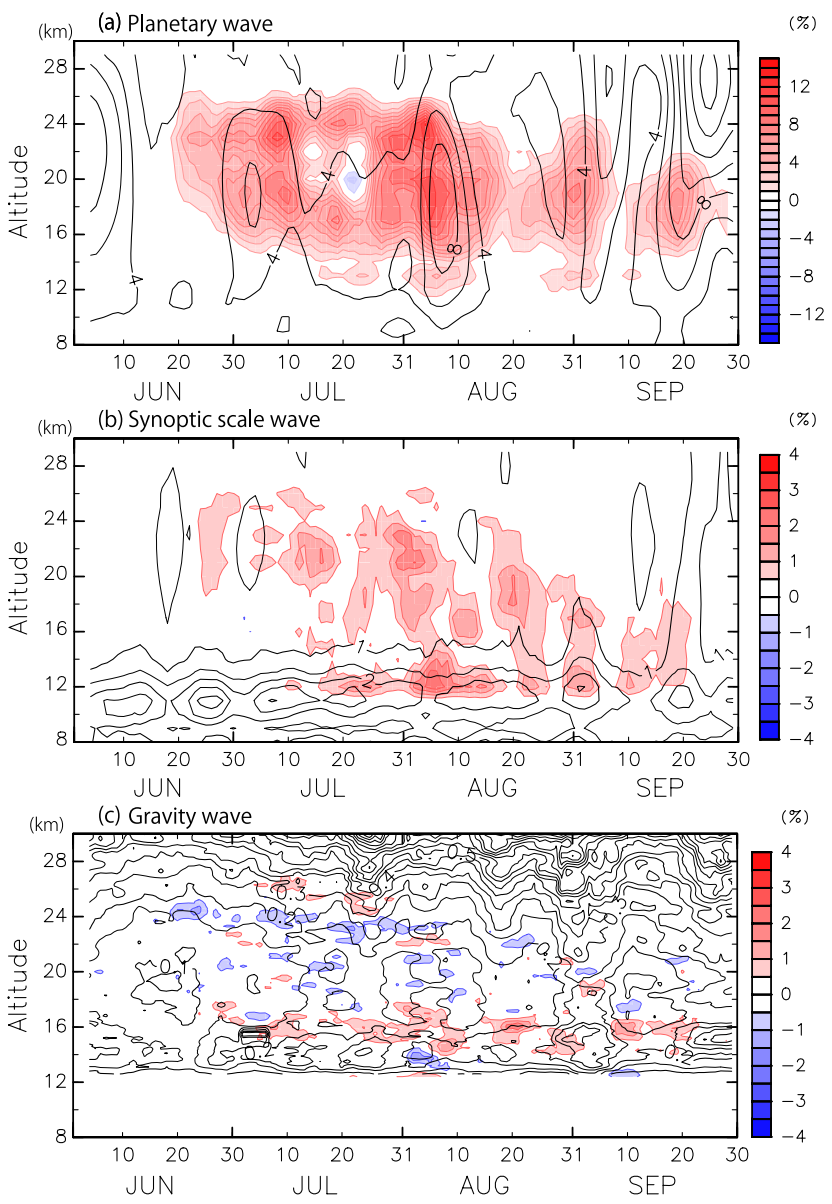

Fig. 10. Time-altitude sections of 5-day-runnning means for (a) $\Delta R_{\mathrm{PW}}$, (b) $\Delta R_{\mathrm{SW}}$ and (c) $\Delta R_{\mathrm{GW}}$ (color) in the latitude range of $55^{\circ} \mathrm{S}-70^{\circ} \mathrm{S}$. A $500 \mathrm{~m}$-running mean is applied to $\Delta R_{\mathrm{GW}}$ in the vertical direction. Contours indicate the zonal-mean and latitudinalmean $\left(55^{\circ} \mathrm{S}-70^{\circ} \mathrm{S}\right)$ standard deviation of temperature fluctuations due to the respective waves. Contour intervals are $2 \mathrm{~K}$ for $(\mathbf{a}), 0.5 \mathrm{~K}$ for (b) and $0.05 \mathrm{~K}$ for (c).

Similar analyses are conducted to obtain $\Delta R_{\mathrm{SW}}$ and $\Delta R_{\mathrm{GW}}$ for synoptic-scale waves $(s=4-20)$ and gravity waves (vertical wavelength $<6 \mathrm{~km}$ ), respectively. For calculations of PSC coverage ratios with and without gravity waves, unfiltered $\mathrm{HNO}_{3}$ and $\mathrm{H}_{2} \mathrm{O}$ mixing ratios are used because the original vertical resolutions of $\mathrm{HNO}_{3}$ and $\mathrm{H}_{2} \mathrm{O}$ data are not as high as that of COSMIC temperature data.

Figure 10a-c show time-altitude sections of 5-day-runnnig means for $\Delta R_{\mathrm{PW}}, \Delta R_{\mathrm{SW}}$ and $\Delta R_{\mathrm{GW}}$. Red (blue) areas indicate an increase (decrease) in PSC coverage ratios. Contours show the standard deviation of temperature fluctuations associated with the respective waves. The standard deviation of planetary waves is large at altitudes of $13-25 \mathrm{~km}$ in early July and early August. In September, the standard deviation becomes larger, having its peak around an altitude of $28 \mathrm{~km} . \Delta R_{\mathrm{PW}}$ is about $+5 \%$ on average at altitudes of $16-25 \mathrm{~km}$ in the time period of mid-June through Septem-
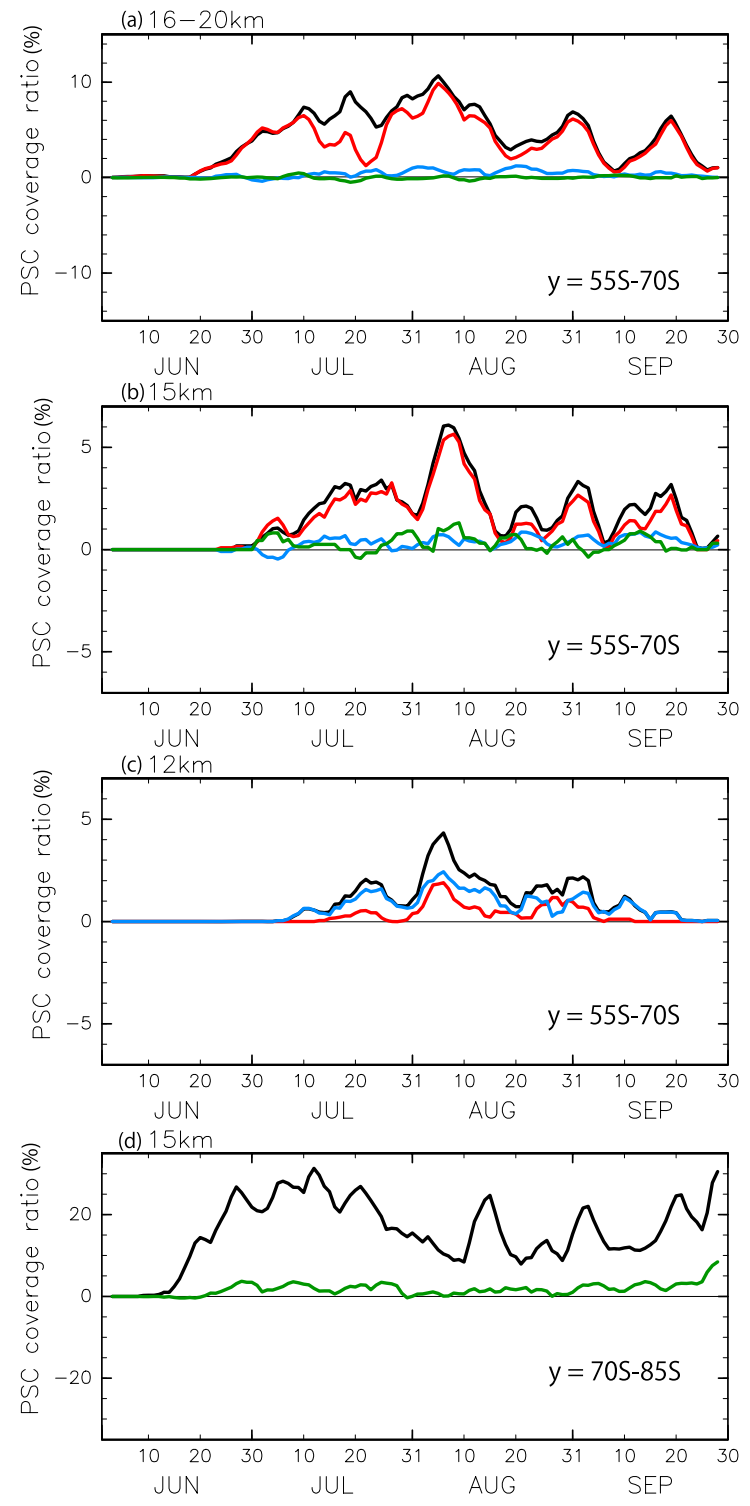

Fig. 11. Time series of 5-day-running means for $\Delta R_{\mathrm{PW}}$ (red), $\Delta R_{\mathrm{SW}}$ (blue) and $\Delta R_{\mathrm{GW}}$ (green) in the latitude range of $55^{\circ} \mathrm{S}$ $70^{\circ} \mathrm{S}$ at altitudes of (a) $16-20 \mathrm{~km}$, (b) $15 \mathrm{~km}$ and (c) $12 \mathrm{~km}$. Black curves indicate $R_{\mathrm{ALL}}$. (d) The same as (b) but for $70^{\circ} \mathrm{S}-85^{\circ} \mathrm{S}$. Only a result for gravity waves is shown.

ber. Synoptic-scale waves have large temperature fluctuations around $11 \mathrm{~km}$ in June through September. $\Delta R_{\mathrm{SW}}$ is about $+1 \%$ on average at around $12 \mathrm{~km}$. Positive $\Delta R_{\mathrm{SW}}$ values are seen at altitudes of $16-25 \mathrm{~km}$ in spite of little temperature standard deviation from synoptic-scale waves there.

The temperature standard deviation of gravity waves increases at heights above $16 \mathrm{~km}$ and has a maximum at around $14 \mathrm{~km}$, which is consistent with Yoshiki et al. (2004). $\Delta R_{\mathrm{GW}}$ is positive at altitudes of $13-16 \mathrm{~km}$ and negative at altitudes of $22-25 \mathrm{~km}$. However, the effect is small compared with those of planetary and synoptic-scale waves. 

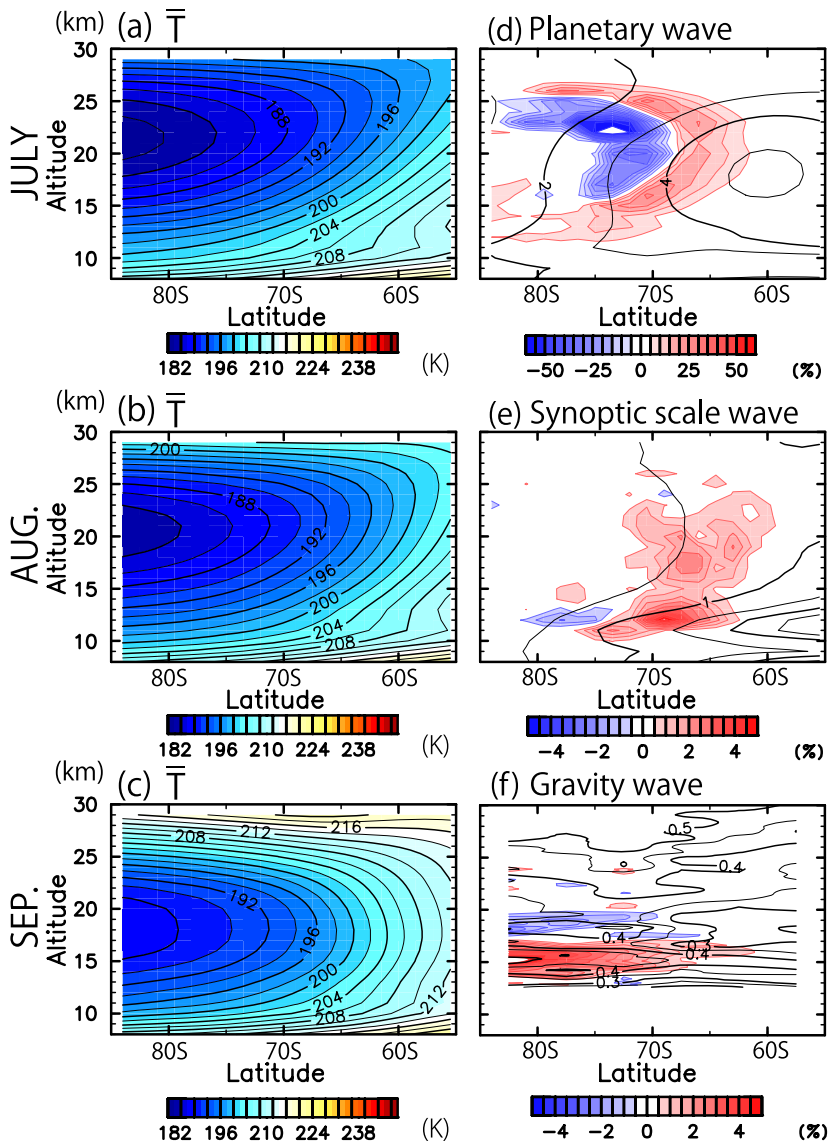

Fig. 12. (a-c) Latitude-altitude sections of zonal-mean and monthly-mean temperature in July through September. Contour intervals are $2 \mathrm{~K}$. (d-f) Latitude-altitude sections of zonal-mean and monthly-mean difference of PSC frequency $\Delta F$ between with and without (d) planetary waves in July, (e) synoptic-scale waves in August and (f) gravity waves in September. Positive values mean an increase in PSC frequency. Black contours indicate temperature standard deviation due to the respective waves. Contour intervals are $1 \mathrm{~K}$ for $(\mathbf{d}), 0.5 \mathrm{~K}$ for $(\mathbf{e})$ and $0.05 \mathrm{~K}$ for $(\mathbf{f})$.

Next, the relative contributions of the respective waves to total $T_{\mathrm{STS}}$-based PSC areal extent $R_{\mathrm{ALL}}$ ( $s=$ all wavenumbers) are examined for the latitude range of $55^{\circ} \mathrm{S}-$ $70^{\circ} \mathrm{S} . R_{\mathrm{ALL}}$ is calculated based on unfiltered temperature and mixing ratios of $\mathrm{HNO}_{3}$ and $\mathrm{H}_{2} \mathrm{O}$. The latitude range of $55^{\circ} \mathrm{S}-70^{\circ} \mathrm{S}$ is chosen because PSCs there play a significant role in ozone destruction chemistry. Figure 11a-c show time series of $\Delta R_{\mathrm{PW}}, \Delta R_{\mathrm{SW}}, \Delta R_{\mathrm{GW}}$ and $R_{\mathrm{ALL}}$ at altitudes of $16-20 \mathrm{~km}, 15 \mathrm{~km}$ and $12 \mathrm{~km}$ for $55^{\circ} \mathrm{S}-70^{\circ} \mathrm{S}$. These altitude ranges are analyzed because the changes in $R$ due to the respective waves are large, as seen in Fig. 10.

$\Delta R_{\mathrm{PW}}$ accords with $R_{\mathrm{ALL}}$ at altitudes of $16-20 \mathrm{~km}$, indicating that the contribution of planetary waves is dominant, except for 8-27 July. The small $\Delta R_{\mathrm{PW}}(<4 \%)$ during 8-27 July is most likely due to the small planetary wave amplitudes (see Fig. 10a). This feature suggests that zonal-mean temperature is lower than $T_{\mathrm{STS}}$ during this time period compared with other time periods. At $12 \mathrm{~km}, \Delta R_{\mathrm{SW}}$ is larger than $\Delta R_{\mathrm{PW}}$, indicating that the effects of synoptic-scale waves are dominant. The ratio of $\Delta R_{\mathrm{SW}}$ to $R_{\mathrm{ALL}}$, i.e. contribution of synoptic-scale waves at $12 \mathrm{~km}$ is more than $60 \%$ on average. At an altitude of $15 \mathrm{~km}$, where the effects of gravity waves are large (Fig. 10c), $\Delta R_{\mathrm{GW}}$ is comparable to $\Delta R_{\mathrm{SW}}$ but smaller than $\Delta R_{\mathrm{PW}}$, suggesting that gravity waves have a small impact on PSC coverage ratio. The ratio of $\Delta R_{\mathrm{GW}}$ to $R_{\mathrm{ALL}}$, i.e. contribution of gravity waves, is about $15 \%$ in late August and September. However, the effect of gravity waves gets larger in the higher latitudes. Figure $11 \mathrm{~d}$ shows time series of $\Delta R_{\mathrm{GW}}$ and $R_{\mathrm{ALL}}$ at an altitude of $15 \mathrm{~km}$ in the latitude range of $70^{\circ} \mathrm{S}-85^{\circ} \mathrm{S}$. The contribution of gravity waves to $R_{\mathrm{ALL}}$ amounts to about $30 \%$ on average in September.

Figure 12a-c show latitude-altitude sections of the zonalmean monthly-mean temperature in July, August and September, respectively. Figure $12 \mathrm{~d}-\mathrm{f}$ show the same as Fig. $12 \mathrm{a}-\mathrm{c}$ but for the difference $\Delta F$ between $T_{\mathrm{STS}}$-based PSC frequencies $F$ with and without planetary waves in July in each grid box (Fig. 12d), synoptic-scale waves in August (Fig. 12e) and gravity waves in September (Fig. 12f), respectively. These time periods are chosen because the changes of PSC areal extent due to the respective waves are large in Fig. 10. Contour lines indicate the temperature standard deviation associated with the respective waves. In July, $\Delta F$ due to planetary waves are positive to the north of $70^{\circ} \mathrm{S}$ in an altitude range of $15-23 \mathrm{~km}$ and negative at higher latitudes in the same altitude range. This is probably reflecting the fact that zonal-mean temperature is lower (higher) than $T_{\mathrm{STS}}$ to the south (north) of $70^{\circ} \mathrm{S}$. The negative $\Delta F$ at the higher latitudes is not meaningful because $T_{\text {STS }}$-based PSC frequency estimates are not accurate there, as is described in Sect. 3 (see Fig. 4).

Figure $12 \mathrm{~b}$ shows that the temperature standard deviation of synoptic-scale waves is maximized around an altitude of $12 \mathrm{~km}$ in August and that $\Delta F$ due to synoptic-scale waves is positive there. Another interesting feature is that $\Delta F$ is significantly positive at altitudes of $16-25 \mathrm{~km}$ for the latitude range of $50^{\circ} \mathrm{S}-70^{\circ} \mathrm{S}$, even though the standard deviation is almost zero at latitudes higher than $70^{\circ} \mathrm{S}$ and above $15 \mathrm{~km}$. This feature is observed also in the other months. The positive $\Delta F$ in $16-25 \mathrm{~km}$ may not be due to synoptic-scale waves but the synoptic-scale structure of the distribution of $\mathrm{HNO}_{3}$ and/or $\mathrm{H}_{2} \mathrm{O}$ mixing ratios caused by inhomogeneous denitrification and dehydration. This point will be discussed in the Discussion section.

In Fig. 12c, temperature standard deviation due to gravity waves observed in a wide latitude range of $55^{\circ} \mathrm{S}-85^{\circ} \mathrm{S}$ are similar to those of Fig. 10c. A Positive $\Delta F$ due to gravity waves around an altitude of $15 \mathrm{~km}$ is more significant at latitudes higher than $65^{\circ} \mathrm{S}$ in September, which is consistent with Fig. 11d.

Figure 13 shows polar stereo projection maps of the monthly-mean $\Delta F$ due to the respective waves. The altitudes 


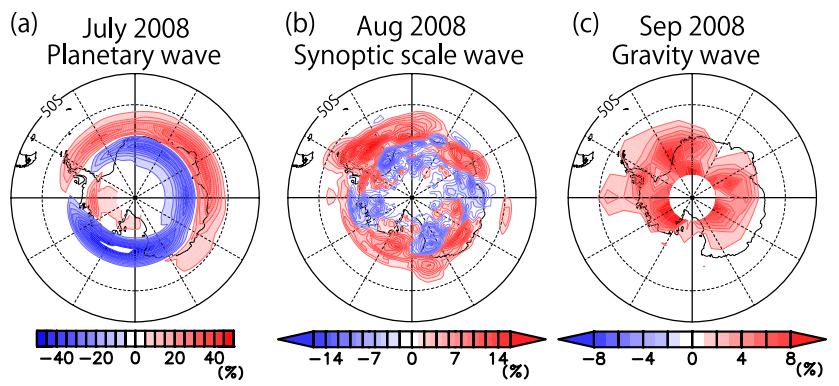

Fig. 13. Polar stereo projection maps of monthly-mean $\Delta F$ (a) due to planetary waves at $16-20 \mathrm{~km}$ in July, (b) due to synoptic-scale waves at $12 \mathrm{~km}$ in August and (c) due to gravity waves at $15 \mathrm{~km}$ in September.

and months shown in each panel are chosen because they have the highest magnitudes of $\Delta F$ for each wave in Fig. 10: $z=16-20 \mathrm{~km}$ in July for planetary waves (Fig. 13a), $z=$ $12 \mathrm{~km}$ in August for synoptic-scale waves (Fig. 13b) and $z=15 \mathrm{~km}$ in September for gravity waves (Fig. 13c). Planetary waves act to increase PSC frequency to the north of $70^{\circ} \mathrm{S}$. PSC frequency to the south of $70^{\circ} \mathrm{S}$ decreases, which may not be meaningful, as noted in Sect. 3 .

In the austral winter, propagating planetary waves are dominant around the polar vortex. These planetary waves are accompanied by temperature fluctuations, as is illustrated in Fig. 5. It is likely that the warm temperature advection at the higher latitudes and cold advection at the lower latitudes cause the annular-like structure of $\Delta F$, as can be observed in Fig. 13a.

In Fig. 13b, $\Delta F$ due to synoptic-scale waves is mostly positive at lower latitudes and negative at higher latitudes, even though a horizontal pattern of zonal wavenumber 4 is observed. The wavy pattern is probably due to synoptic-scale waves being temporally amplified in August.

Gravity waves increase PSC frequency at altitudes of 11$15 \mathrm{~km}$, in particular over the Transantarctic Mountains and downstream of the Antarctic Peninsula (Fig. 13c).

\section{The effects of atmospheric waves on PSCs in the Arctic winter of 2007/2008}

PSCs appear less frequently in the Arctic than in the Antarctic. Figure 14 shows longitude-time sections of PSC frequency observed by CALIPSO and the $T_{\mathrm{STS}}$-based PSC frequency for the latitude range of $65^{\circ} \mathrm{N}-70^{\circ} \mathrm{N}$ in December 2007 through February 2008. Note that data during 28-31 December and 17 January are missing. The $T_{\mathrm{STS}}$-based estimates accord well with CALIPSO observations in Fig. 14, although they are a little larger. Unlike the Southern Hemisphere estimates, the $T_{\mathrm{STS}}$-based estimates are consistent with observations even at higher latitudes $\left(>70^{\circ} \mathrm{N}\right)$, which is likely due to the weak denitrification and dehydration in the

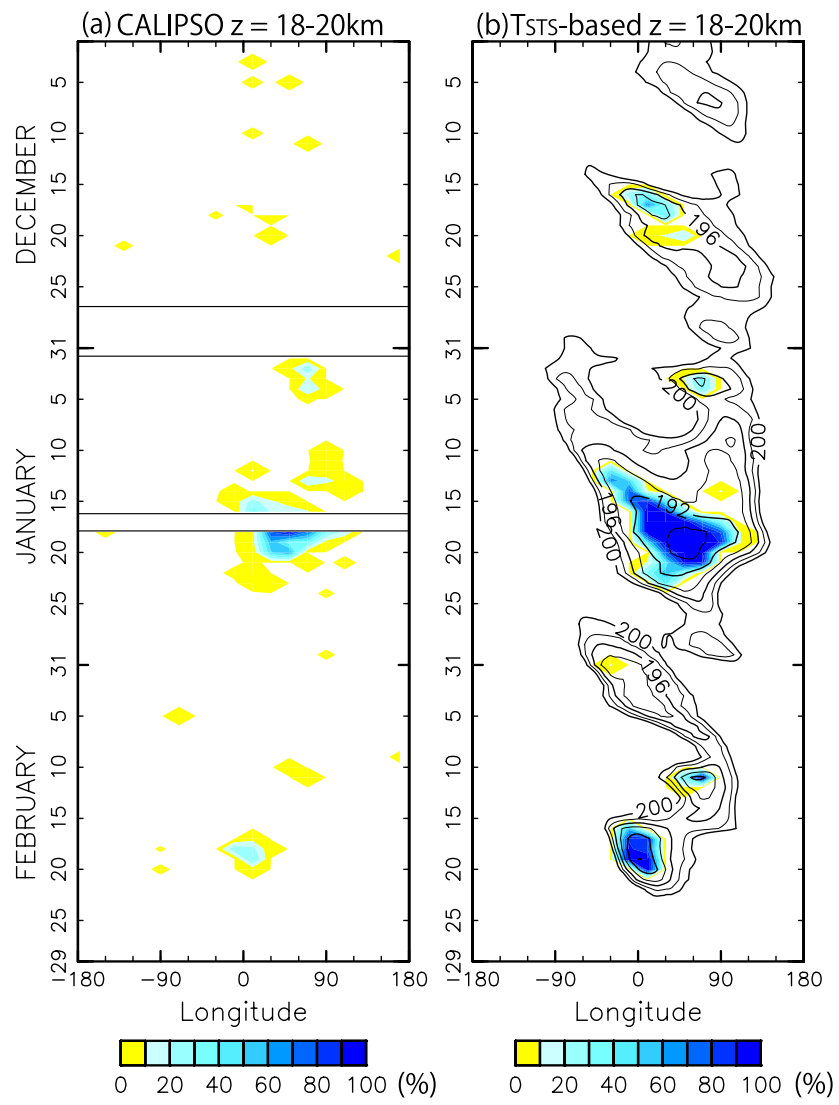

Fig. 14. The same as Fig. 3 but for the latitude range of $65^{\circ} \mathrm{N}-$ $70^{\circ} \mathrm{N}$ in the winter of 2007/2008.

Northern Hemisphere. Compared with the Southern Hemisphere, PSCs are observed less frequently in the Northern Hemisphere, and they are restricted to the longitudes between $0^{\circ}$ and $90^{\circ} \mathrm{E}$. This is probably because the winter stratosphere is generally warmer in the Arctic than in the Antarctic. Also, the center of the polar vortex shifts to Europe due to stationary planetary waves. Interannual variation of PSCs is larger in the Northern Hemisphere, reflecting strong planetary wave activity. For example, PSC frequency was low in the winter of 2008/2009 when a stratospheric major warming occurred (not shown).

Figure 15a and $\mathrm{b}$ show time-altitude sections of observed and $T_{\mathrm{STS}}$-based PSC areal extents in the Northern Hemisphere, respectively. The observed PSC areal extent in the Northern Hemisphere is about half of that in the Southern Hemisphere. In addition, the vertical extent of PSCs is smaller in the Northern Hemisphere. PSCs are sparse below $16 \mathrm{~km}$.

The $T_{\mathrm{STS}}$-based PSC areal extent is about twice as large as the observations at altitudes of $16-25 \mathrm{~km}$ during the winter. This may be because optically thin clouds, which cannot be detected by CALIOP, are more frequent in the Northern Hemisphere than in the Southern Hemisphere. However, it should be noted that the timings and altitudes where PSC 
areal extent is maximized are consistent with the CALIPSO observations. Thus, to examine the effects of atmospheric waves in the Northern Hemisphere, $T_{\mathrm{STS}}$-based PSC frequency estimates are used, as they were used for the Southern Hemisphere in Sect. 5.

Figure 15c-e show time-altitude sections of 5-day-running means for $\Delta R_{\mathrm{PW}}, \Delta R_{\mathrm{SW}}$ and $\Delta R_{\mathrm{GW}}$ (colors) and temperature standard deviation (contours) in the latitude range of $55^{\circ} \mathrm{N}-85^{\circ} \mathrm{N}$ in December 2007 through February 2008. Note that the analyzed latitude range in the Northern Hemisphere is larger than that in the Southern Hemisphere, which covers almost the whole area where PSCs are observed, except near the North Pole.

As is seen in Fig. 15c, the temperature standard deviation of planetary waves is much larger in the Northern Hemisphere than in the Southern Hemisphere at altitudes above $12 \mathrm{~km}$. Values of $\Delta R_{\mathrm{PW}}$ are about $10 \%$ on average at altitudes of $18-27 \mathrm{~km}$ in the time period of mid-December through early February. In particular, $\Delta R_{\mathrm{PW}}$ is largely positive when and where planetary waves have large amplitudes.

Figure $15 \mathrm{~d}$ shows that the standard deviation of temperature fluctuations associated with synoptic-scale waves is large around $11 \mathrm{~km}$ during the winter. The increase in PSC areal extent in the lowermost stratosphere, as is clearly seen in the Southern Hemisphere, is not so obvious in the Northern Hemisphere (see Fig. 10b).

The large temperature standard deviation of synoptic-scale waves is observed above $24 \mathrm{~km}$ during 20-30 January when a sudden stratospheric warming occurred (Fig. 1). In the time period of the sudden stratospheric warming, the polar vortex was highly distorted and the zonal wavenumber spectra were spread over a wide range including synoptic-scales (not shown), which is considered to cause negative values of $\Delta R_{\mathrm{SW}}$.

Significant negative values of $\Delta R_{\mathrm{SW}}$ are observed at altitudes of $16-24 \mathrm{~km}$ in January through mid-February, even though the standard deviation of temperature fluctuations associated with synoptic-scale waves is not necessarily large (e.g. 5-20 January). Similar to the significant positive $\Delta R_{\mathrm{SW}}$ in $16-25 \mathrm{~km}$ in the Southern Hemisphere, the negative $\Delta R_{\mathrm{SW}}$ in $16-24 \mathrm{~km}$ may be due to the synoptic-scale structure of the distribution of $\mathrm{HNO}_{3}$ and/or $\mathrm{H}_{2} \mathrm{O}$ mixing ratios.

Temperature standard deviation of gravity waves peaks at around $15 \mathrm{~km}$, and increases with height above $16 \mathrm{~km}$ (Fig. 15e), which is similar to the Southern Hemisphere. $\Delta R_{\mathrm{GW}}$ is generally quite small but is slightly negative at altitudes of 16-24 km in the time period of 5-25 January.

The relative contributions of the respective waves to the total $T_{\mathrm{STS}}$-based PSC areal extent $R_{\mathrm{ALL}}$ are examined. Figure 16 shows time series of $\Delta R_{\mathrm{PW}}, \Delta R_{\mathrm{SW}}, \Delta R_{\mathrm{GW}}$ and $R_{\mathrm{ALL}}$ for the latitude range of $55^{\circ} \mathrm{N}-85^{\circ} \mathrm{N}$ at $22 \mathrm{~km}$, where PSCs were most frequently observed in the winter of 2007/2008. The contribution of planetary waves to $R_{\mathrm{ALL}}$ is dominant during winter, while those of synoptic-scale waves and grav-
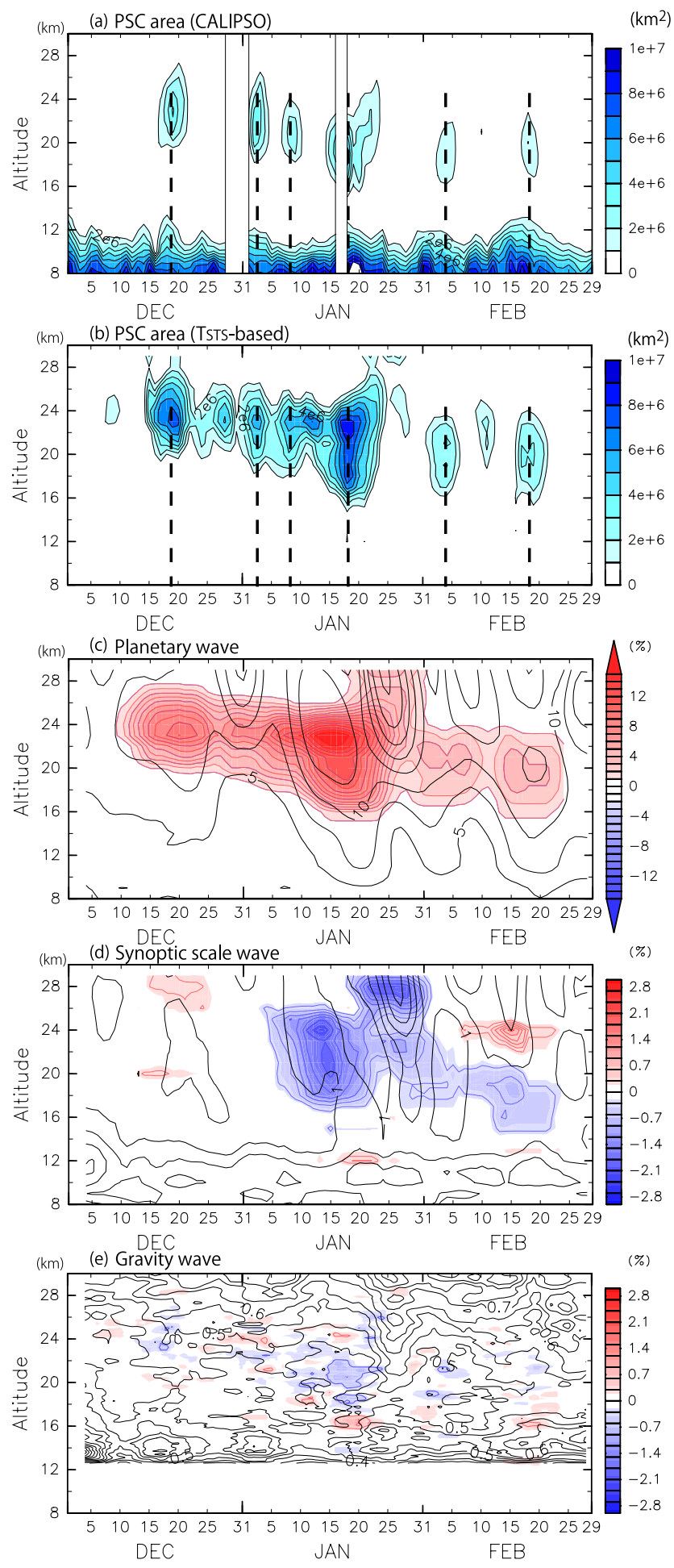

Fig. 15. (a) and (b) The same as Fig. 8 but for the latitude range of $55^{\circ} \mathrm{N}-85^{\circ} \mathrm{N}$ in the $2007 / 2008$ winter. (c-e) The same as Fig. 10 but for the the latitude range of $55^{\circ} \mathrm{N}-85^{\circ} \mathrm{N}$ in the $2007 / 2008$ winter. Contour intervals are $2.5 \mathrm{~K}$ for $(\mathbf{a}), 0.5 \mathrm{~K}$ for $(\mathbf{b})$ and $0.05 \mathrm{~K}$ for (c). 


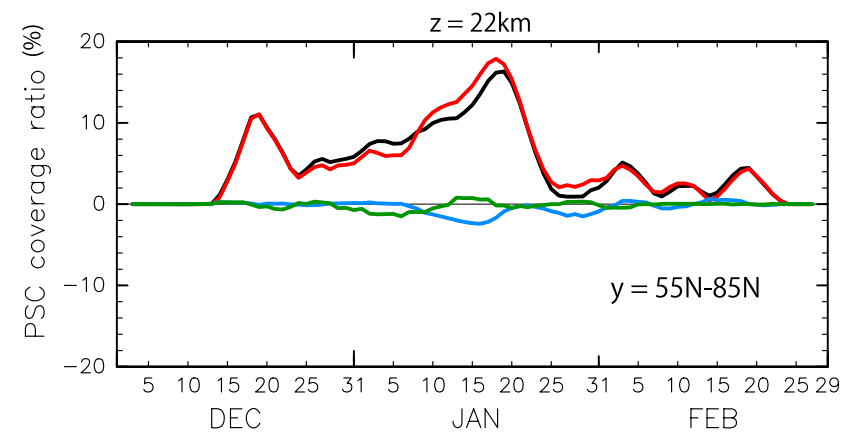

Fig. 16. The same as Fig. 11 but for the latitude range of $55^{\circ} \mathrm{N}-$ $85^{\circ} \mathrm{N}$ at an altitude of $22 \mathrm{~km}$ in December 2007 through February 2008.

ity waves are small. It is interesting to note that $\Delta R_{\mathrm{PW}}$ exceeds $R_{\mathrm{ALL}}$ in mid-January, and that the excess is cancelled by $\Delta R_{\mathrm{SW}}$. It is worth noting that the results displayed in Fig. 16 are for the latitude range of $55^{\circ} \mathrm{N}-85^{\circ} \mathrm{N}$, while those in Fig. 11 are only for the lower latitude range of $55^{\circ} \mathrm{S}-$ $70^{\circ} \mathrm{S}$. Although the contribution of zonal-mean fields to PSC formation is important at higher latitudes in the Southern Hemisphere, most PSCs in the Northern Hemisphere are caused by planetary waves, so the contribution of zonal-mean fields is quite small.

Figure 17 shows polar stereo projection maps of monthlymean $\Delta F$ due to planetary waves in January at $22 \mathrm{~km} . \Delta F$ due to planetary waves is positive in the longitude range of $30^{\circ} \mathrm{W}-120^{\circ} \mathrm{E}$. In the Arctic stratosphere, stationary planetary waves are dominant, usually shifting the center of the polar vortex to Europe. Thus, the region where $T \leq T_{\mathrm{STS}}$ is restricted to the longitude range of about $30^{\circ} \mathrm{W}-90^{\circ} \mathrm{E}$.

\section{Discussion}

\subsection{The contribution of planetary waves}

In this study, to quantify the contribution of each wave to PSC areal extent, the difference between the estimated areal extents with and without the wave was examined. As a result, it was shown that the contribution of planetary waves is dominant in the both hemispheres. However, a special attention should be paid to these results, particuraly about planetary waves because the contribution of planetary waves may contain inherently that of zonal mean field. To specify this problem, let us consider an ideal situation such that temperatures inside (outside) the circular polar vortex are lower (higher) than $T_{\mathrm{STS}}$ and that the vortex center shifts from the pole to a particular direction. In this situation, the contribution of planetary waves to $R_{\mathrm{ALL}}$ estimated by the present method can take non-zero values, although the PSC coverage ratio is the same as that without the vortex shift. In this way, a part of

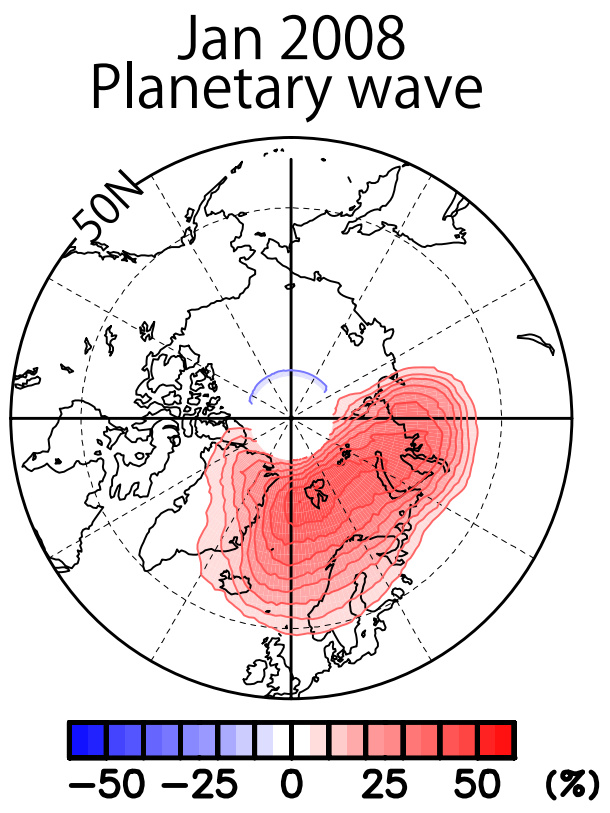

Fig. 17. The same as Fig. 13a but for January 2008 in the Northern Hemisphere at an altitude of $22 \mathrm{~km}$.

the contribution of the shifted polar vortex can be interpreted as that of planetary waves in this study.

Next, let us consider the meaning of the vortex shift. As the center of vortex shifts from the pole, the proportion of PSCs in the lower latitudes increases. As mentioned in Sect. 3, PSCs in the lower latitudes are more effective in depletion of stratospheric ozone because the sun light arrives earlier at the lower latitudes than higher latitudes in spring. Thus, increase in PSC coverage ratio due to the vortex shift tends to promote the destruction of stratospheric ozone.

Note that the other planetary wave components, such as $s=2-3$, also have PSC areal extent increase in the lower latitudes and thus accelerate ozone depletion. Futhermore, all planetary waves $(s=1-3)$ can affect the PSC coverage ratio quantitatively in a similar manner to the synoptic-scale waves (see Fig. 6). Thus, the change in PSC coverage ratio due to planetary waves expresses a mixture of two effects: change in the proportion of PSCs in the lower latitudes and change in PSC coverage ratio due to the temperature modulation by planetary waves. Both effects modulate ozone depletion in the stratosphere. Thus, it may be more appropriate to interpret $\Delta R_{\mathrm{PW}}$ defined in this study as the contribution of planetary waves to the ozone depletion.

\subsection{The contribution of synoptic-scale waves above $15 \mathrm{~km}$}

It was shown in Fig. $10 \mathrm{~b}$ and $\mathrm{d}$ that the contribution of synoptic-scale waves to the PSC coverage ratio, $\Delta R_{\mathrm{SW}}$, is large in the altitude range of $15-24 \mathrm{~km}$ in the Southern Hemisphere and in $15-26 \mathrm{~km}$ in the Northern Hemisphere, 
although the standard deviation of temperature fluctuations associated with synoptic-scale waves is not always large $(<1 \mathrm{~K})$ there. A possible explanation for the large $\Delta R_{\mathrm{SW}}$ may be due to the filament structure in $\mathrm{HNO}_{3}$ and $\mathrm{H}_{2} \mathrm{O}$ distributions with synoptic-scales that are caused by the deformed polar vortex. Thus, $\Delta R_{\mathrm{SW}}$ may contain a part of the contribution of planetary scale waves. However, because the $\mathrm{HNO}_{3}$ and $\mathrm{H}_{2} \mathrm{O}$ from MLS does not have such a sufficient resolution that capture the filament structure, further analysis is left for the future studies.

\section{Summary and concluding remarks}

The effects of atmospheric waves on the amounts of PSCs in both hemispheres have been examined using observation data from the three satellites CALIPSO, COSMIC and Aura MLS and reanalysis data.

PSC frequency is calculated using CALIPSO VFM data in the Southern Hemisphere in the winter of 2008. A Hovmöller diagram indicates that the high PSC frequency regions propagate eastward at speeds that are much different from the background zonal wind, suggesting significant modulation due to atmospheric waves.

Next, PSC frequency is estimated based on three kinds of temperature thresholds and compared with CALIPSO observations. For the estimations, temporal and spatial variations of $\mathrm{HNO}_{3}$ and $\mathrm{H}_{2} \mathrm{O}$ mixing ratios observed by MLS are used. The history of air-parcels, such as advection of the existing particles, is ignored. Although $T_{\mathrm{STS}}$-based PSC frequency accords well with the observations in the latitude ranges of $55^{\circ} \mathrm{S}-70^{\circ} \mathrm{S}$ and $55^{\circ} \mathrm{N}-85^{\circ} \mathrm{N}$, the estimation is not consistent with observations in the regions to the south of $70^{\circ} \mathrm{S}$, in particular in midwinter. This inconsistency at the higher latitudes in the Southern Hemisphere is likely due to extremely low mixing ratios of $\mathrm{HNO}_{3}$ and/or $\mathrm{H}_{2} \mathrm{O}$. However, the $T_{\mathrm{ICE}}{ }^{-}$ based PSC frequency is consistent with the observations at higher latitudes. This result for the Southern Hemisphere suggests that PSCs mainly consist of STS at lower latitudes, while water ice is dominant at higher latitudes, which is consistent with previous observational study (e.g. Höphner et al., 2006).

The relationships between temperature fluctuations and planetary waves in the middle stratosphere and with synoptic-scale waves near the tropopause are then examined. It is shown by a scatter diagram analysis that planetary-scale cyclones are accompanied with negative temperature anomalies with amplitudes of about $10 \mathrm{~K}$ at $65^{\circ} \mathrm{S}$ and at around $20 \mathrm{~km}$. In contrast, synoptic-scale anticyclones with potential vorticity anomalies near the tropopause are accompanied with negative temperature fluctuations with amplitudes of about $1 \mathrm{~K}$ at $65^{\circ} \mathrm{S}$ and $10-15 \mathrm{~km}$. These results suggest that planetary waves have a great impact on the spatial distribution of PSCs in the middle stratosphere, and synopticscale waves have a great impact at around $12 \mathrm{~km}$, which is consistent with previous case studies by Teitelbaum and Sadourny (1998) and Teitelbaum et al. (2001).

The effects of gravity waves are examined using COSMIC data. Gravity wave components are defined as fluctuations with vertical wavelengths shorter than $6 \mathrm{~km}$. It is confirmed that low temperatures due to gravity waves accord with PSCs observed by CALIPSO.

Following this, the effects of three kinds of atmospheric waves (planetary, synoptic-scale and gravity waves) on PSC areal extents are examined by analyzing the change in the $T_{\text {STS-based PSC coverage ratio due to the respective waves }}$ for a latitude region of $55^{\circ} \mathrm{S}-70^{\circ} \mathrm{S}$. It is shown that at 16 $22 \mathrm{~km}$, planetary waves increase the PSC coverage ratio by about $5 \%$ on average in the examined latitude range in midJune through September, which is almost the same as total PSC coverage ratio. In other words, PSCs in this area are mainly caused by planetary waves during winter. This is likely due to the fact that zonal-mean temperature is usually higher than $T_{\mathrm{STS}}$ at lower latitudes $\left(55^{\circ} \mathrm{S}-70^{\circ} \mathrm{S}\right)$ and that the most significant cause of low temperature $\left(<T_{\mathrm{STS}}\right)$ is modulation due to the propagating planetary waves along the polar night jet situated at about $60^{\circ} \mathrm{S}$ in the Antarctic stratosphere. The temperature fluctuations associated with synoptic-scale waves are dominant at around $12 \mathrm{~km}$ in winter. The change in PSC coverage ratio $\Delta R$ is about $+1 \%$ at around $12 \mathrm{~km}$, which means that the relative contribution of synoptic-scale waves to the total PSC coverage ratio at $12 \mathrm{~km}$ is more than $60 \%$.

It is also shown that the gravity wave effects are significant at around $15 \mathrm{~km}$ at latitudes higher than $70^{\circ} \mathrm{S}$, in particular in September ( $\triangle R \sim 3 \%$; relative contribution to total of $\sim 30 \%)$, although they are smaller $(\Delta R \sim 0.1 \%$; relative contribution of $\sim 15 \%)$ at lower latitudes $\left(55^{\circ} \mathrm{S}-70^{\circ} \mathrm{S}\right)$. Alexander et al. (2011) shows that $30 \%$ of PSCs in the latitude range of $60^{\circ} \mathrm{S}-70^{\circ} \mathrm{S}$ in the altitudes of $400-700 \mathrm{~K}(\sim 15-30 \mathrm{~km})$ are attributable to orographic gravity waves using COSMIC and Aura MLS data. It is likely to that the discrepancy between Alexander et al. (2011) and our results mainly comes from the difference of the cutoff vertical wavelengths which are used in the definition of gravity waves. When the cutoff wavelength is chosen as $15 \mathrm{~km}$ instead of $6 \mathrm{~km}, \Delta R_{\mathrm{GW}}$ turns out to be about $2 \%$ (relative contribution of $\sim 20 \%$ ) in the lower latitudes through the winter in $16-20 \mathrm{~km}$ on average (not shown). However, the wavelength of $6 \mathrm{~km}$ is still adopted in this study to avoid contamination of planetary waves and synoptic-scale waves as discussed in Sect. 4.2.

Similar analyses are performed for the Northern Hemisphere winter in 2007/2008, where PSC regions are significantly limited. The $T_{\mathrm{STS}}$-based estimates of PSC areal extent accord well with observations in most latitudes of $55^{\circ} \mathrm{N}-$ $85^{\circ} \mathrm{N}$ in terms of temporal variation. However, the $T_{\mathrm{STS}^{-}}$ based PSC areal extent is about twice as large as observations at $16-25 \mathrm{~km}$ during winter. This may be because the proportion of optically thin clouds, which are hardly detected by 
CALIOP, is higher in the Northern Hemisphere than in the Southern Hemisphere.

Stationary planetary waves are dominant in the Arctic stratosphere and strongly affect PSC areal extents. Their relative contribution to the total PSC coverage ratio is close to $100 \%$ at most altitudes during the winter. Synoptic-scale waves and gravity waves act to decrease PSC coverage area, although their effects are very weak.

Several studies have examined the relationship between ozone depletion and PSC areal extent and volume (areal extent times the altitude range) based on $T_{\mathrm{NAT}}$ in the Northern Hemisphere (e.g. Rex et al., 1999, 2004). The results in this study suggest that $T_{\mathrm{NAT}}$-based PSC areal extent may overestimate actual PSC areal extent because $T_{\text {STS }}$ is lower than $T_{\mathrm{NAT}}$, which is consistent with Pitts et al. (2007).

Several previous studies have emphasized the importance of synoptic-scale waves near the tropopause and gravity waves in the Northern Hemisphere. For example, Teitelbaum et al. (2001) indicated the importance of uplifts of isentropic surface due to synoptic-scale anticyclonic potential vorticity anomalies near the tropopause. However, due to the small latitude circles in the polar region, the uplifts of isentropic surface analyzed by Teitelbaum et al. (2001) may have had larger spatial scales than those analyzed as synoptic-scale ( $s=4-20)$ waves in the present study. Thus, it is possible that the effects of synoptic-scale waves as analyzed by Teitelbaum et al. (2001) are included in $\Delta R_{\mathrm{PW}}$ of the present study. For a more detailed evaluation of the effects of atmospheric waves on PSCs, the history of air parcels would need to be considered. Several studies (e.g. Eckermann et al. 2009) have shown that water ice formed at low temperatures in association with gravity waves helps NAT formation. In this study, gravity waves with horizontal wavelengths shorter than about $600 \mathrm{~km}$ were not detected in COSMIC observations, although gravity waves with much shorter horizontal wavelengths do exist. Thus, it is possible that our study underestimates the effects of gravity waves on PSC areal extent. Therefore, a further analysis of the effects of gravity waves on PSCs using data from higher resolution observations and numerical models is needed.

Acknowledgements. We thank H. Nakamura and M. Koike for their many useful comments and discussions. We appreciate constructive and useful comments from $\mathrm{D}$. Wu at NASA Jet Propulsion Laboratory and S. T. Massie at National Center for Atmospheric Research about CALIPSO data and Aura MLS data. We are also indebted to Y. Tomikawa at the National Institute of Polar Research for his help to treat of ERA-Interim data. The figures were drawn by the software tools developed under the GFD Dennou Club Davis project. The CALIPSO data product is available at NASA Langley Atmospheric Science Data Center (http://eosweb.larc.nasa.gov/). The Aura MLS data product is available at NASA Goddard Earth Sciences Data and Information Service Center (GES-DISC; http://disc.gsfc.nasa.gov). This study is supported by Grant-in-Aid for Scientific Research (B) 22340134 and by Grant-in-Aid for Research Fellow (23-9377) of the Japan
Society for the Promotion of Science (JSPS). This manuscript was proofread by a proofreading/editing assistant from the Global COE program, From the Earth to "Earths".

Edited by: W. Ward

\section{References}

Alexander, M. J.: Interpretations of observed climatological patterns in stratospheric gravity wave variance, J. Geophys. Res., 103, 8627-8640, doi:10.1029/97JD03325, 1998.

Alexander, S. P., Klekociuk, A. R., Pitts, M. C., McDonald, A. J., and Arevalo-Torres, A.: The effect of orographic gravity waves on Antarctic polar stratospheric cloud occurrence and composition, J. Geophys. Res., 116, D06109, doi:10.1029/2010JD015184, 2011.

Anthes, R. A., Bernhardt, P. A., Chen, Y., Cucurull, L., Dymond, K. F., Ector, D., Healy, S. B., Ho, S.-P., Hunt, D. C., Kuo, Y.-H., Liu, H., Manning, K., McCormick, C., Meehan, T. K., Randel, W. J., Rocken, C., Schreiner, W. S., Sokolovskiy, S. V., Syndergaard, S., Thompson, D. C., Trenberth, K. E., Wee, T.-K., Yen, N. L., Zeng, Z.: The COSMIC/FORMOSAT-3 Mission: Early Results, B. Am. Meteor. Soc., 89, 313-333, doi:10.1175/BAMS89-3-313, 2008.

Carslaw, K. S., Luo, B. P., Clegg, S. L., Peter, T., Brimblecombe, P., and Crutzen, P. J.: Stratospheric Aerosol Growth and $\mathrm{HNO}_{3}$ Gas-Phase Depletion from Coupled $\mathrm{HNO}_{3}$ and WaterUptake by Liquid Particles, Geophys. Res. Lett., 21, 2479-2482, doi:10.1029/94GL02799, 1994.

Carslaw, K. S., Wirth, M., Tsias, A., Luo, B. P., D”rnbrack, A., Leutbecher, M., Volkert, H., Renger, W., Bacmeister, J. T., Reimer, E., and Peter, T.: Increased stratospheric ozone depletion due to mountain-induced atmospheric waves, Nature, 391, 675-678, doi:10.1038/35589, 1998.

Carslaw, K. S., Peter, T., Bacmeister, J. T., and Eckermann, S. D.: Widespread solid particle formation by mountain waves in the Arctic stratosphere, J. Geophys. Res., 104, 1827-1836, doi:10.1029/1998JD100033, 1999.

Dee, D. P., Uppala, S. M., Simmons, A. J., Berrisford, P., Poli, P., Kobayashi, S., Andrae, U., Balmaseda, M. A., Balsamo, G., Bauer, P., Bechtold, P., Beljaars, A. C. M., van de Berg, L., Bidlot, J., Bormann, N., Delsol, C., Dragani, R., Fuentes, M., Geer, A. J., Haimberger, L., Healy, S. B., Hersbach, H., Holm, E. V., Isaksen, L., Kallberg, P., Kohler, M., Matricardi, M., McNally, A. P., Monge-Sanz, B. M., Morcrette, J. J., Park, B. K., Peubey, C., de Rosnay, P., Tavolato, C., Thepaut, J. N., and Vitart, F.: The ERA-Interim reanalysis: configuration and performance of the data assimilation system, Q. J. Roy. Meteorol. Soc., 137, 553597, doi:10.1002/qj.828, 2011.

Eckermann, S. D., Hoffmann, L., Höpfner, M., Wu, D. L., and Alexander, M. J.: Antarctic NAT PSC belt of June 2003: Observational validation of the mountain wave seeding hypothesis, Geophys. Res. Lett., 36, L02807, doi:10.1029/2008GL036629, 2009.

Fahey, D. W., Gao, R. S., Carslaw, K. S., Kettleborough, J., Popp, P. J., Northway, M. J., Holecek, J. C., Ciciora, S. C., McLaughlin, R. J., Thompson, T. L., Winkler, R. H., Baumgardner, D. G., Gandrud, B., Wennberg, P. O., Dhaniyala, S., McKinney, K., Peter, T., Salawitch, R. J., Bui, T. P., Elkins, J. W., Webster, C. R., 
Atlas, E. L., Jost, H., Wilson, J. C., Herman, R. L., Kleinböhl, A., and von König, M.: The detection of large $\mathrm{HNO}_{3}$-containing particles in the winter Arctic stratosphere, Science, 291, 10261031, 2001.

Fueglistaler, S., Luo, B. P., Voigt, C., Carslaw, K. S., and Peter, Th.: NAT-rock formation by mother clouds: a microphysical model study, Atmos. Chem. Phys., 2, 93-98, doi:10.5194/acp2-93-2002, 2002.

Hanson, D. and Mauersberger, K.: Solubility and equilibrium vapor-pressures of $\mathrm{HCl}$ Dissolved in Polar Stratospheric Cloud Materials - Ice and the Trihydrate of Nitric-Acid, Geophys. Res. Lett., 15, 1507-1510, doi:10.1029/GL015i013p01507, 1988.

Höpfner, M., Larsen, N., Spang, R., Luo, B. P., Ma, J., Svendsen, S. H., Eckermann, S. D., Knudsen, B., Massoli, P., Cairo, F., Stiller, G., v. Clarmann, T., and Fischer, H.: MIPAS detects Antarctic stratospheric belt of NAT PSCs caused by mountain waves, Atmos. Chem. Phys., 6, 1221-1230, doi:10.5194/acp-6-1221-2006, 2006.

Jørgensen, T. S.: On particles in the Arctic stratosphere, Annals of Geophysics, 46, 341-352, 2003.

Koop, T., Ng, H. P., Molina, L. T., and Molina, M. J.: A new optical technique to study aerosol phase transitions: The nucleation of ice from $\mathrm{H}_{2} \mathrm{SO}_{4}$ aerosols, J. Phys. Chem. A, 102, 8924-8931, 1998.

Lambert, A., Read, W. G., Livesey, N. J., Santee, M. L., Manney, G. L., Froidevaux, L., Wu, D. L., Schwartz, M. J., Pumphrey, H. C., Jimenez, C., Nedoluha, G. E., Cofield, R. E., Cuddy, D. T., Daffer, W. H., Drouin, B. J., Fuller, R. A., Jarnot, R. F., Knosp, B. W., Pickett, H. M., Perun, V. S., Snyder, W. V., Stek, P. C., Thurstans, R. P., Wagner, P. A., Waters, J. W., Jucks, K. W., Toon, G. C., Stachnik, R. A., Bernath, P. F., Boone, C. D., Walker, K. A., Urban, J., Murtagh, D., Elkins, J. W., and Atlas, E.: Validation of the Aura Microwave Limb Sounder middle atmosphere water vapor and nitrous oxide measurements, J. Geophys. Res.Atmos., 112, D24S36, doi:10.1029/2007JD008724, 2007.

Lowe, D. and MacKenzie, A. R.: Polar stratospheric cloud microphysics and chemistry, J. Atmos. Sol.-Terr. Phys., 70, 13-40, doi:10.1016/j.jastp.2007.09.011, 2008.

Marti, J. and Mauersberger, K.: Laboratory Simulations of PSC Particle Formation, Geophys. Res. Lett., 20, 359-362, doi:10.1029/93GL00083, 1993.

McDonald, A. J., George, S. E., and Woollands, R. M.: Can gravity waves significantly impact PSC occurrence in the Antarctic?, Atmos. Chem. Phys., 9, 8825-8840, doi:10.5194/acp-9-8825-2009, 2009.

Noel, V., Hertzog, A., Chepfer, H., and Winker, D. M.: Polar stratospheric clouds over Antarctica from the CALIPSO spaceborne lidar, J. Geophys. Res., 113, D02205, doi:10.1029/2007jd008616, 2008.

Pitts, M. C., Thomason, L. W., Poole, L. R., and Winker, D. M.: Characterization of Polar Stratospheric Clouds with spaceborne lidar: CALIPSO and the 2006 Antarctic season, Atmos. Chem. Phys., 7, 5207-5228, doi:10.5194/acp-7-5207-2007, 2007.

Pitts, M. C., Poole, L. R., and Thomason, L. W.: CALIPSO polar stratospheric cloud observations: second-generation detection algorithm and composition discrimination, Atmos. Chem. Phys., 9, 7577-7589, doi:10.5194/acp-9-7577-2009, 2009.

Rex, M., Von Der Gathen, P., Braathen, G. O., Harris, N. R. P., Reimer, E., Beck, A., Alfier, R., Krüger-carstensen, R., Chip- perfield, M., De Backer, H., Balis, D., O'Connor, F., Dier, H., Dorokhov, V., Fast, H., Gamma, A., Gil, M., Kyrö, E., Litynska, Z., Mikkelsen, I. S., Molyneux, M., Murphy, G., Reid, S. J., Rummukainen, M., and Zerefos, C.: Chemical Ozone Loss in the Arctic Winter 1994/95 as Determined by the Match Technique, J. Atmos. Chem., 32, 35-59, doi:10.1023/A:1006093826861, 1999.

Rex, M., Salawitch, R. J., Harris, N. R. P., Gathen, P. v. d., Braathen, G. O., Schulz, A., Deckelmann, H., Chipperfield, M., Sinnhuber, B. M., Reimer, E., Alfier, R., Bevilacqua, R., Hoppel, K., Fromm, M., Lumpe, J., Küllmann, H., Kleinböhl, A., Bremer, H., König, M. v., Künzi, K., Toohey, D., Vömel, H., Richard, E., Aikin, K., Jost, H., Greenblatt, J. B., Loewenstein, M., Podolske, J. R., Webster, C. R., Flesch, G. J., Scott, D. C., Herman, R. L., Elkins, J. W., Ray, E. A., Moore, F. L., Hurst, D. F., Romashkin, P., Toon, G. C., Sen, B., Margitan, J. J., Wennberg, P., Neuber, R., Allart, M., Bojkov, B. R., Claude, H., Davies, J., Davies, W., Backer, H. D., Dier, H., Dorokhov, V., Fast, H., Kondo, Y., Kyrö, E., Litynska, Z., Mikkelsen, I. S., Molyneux, M. J., Moran, E., Nagai, T., Nakane, H., Parrondo, C., Ravegnani, F., Skrivankova, P., Viatte, P., and Yushkov, V.: Chemical depletion of Arctic ozone in winter 1999/2000, J. Geophys. Res., 107, 8276, doi:10.1029/2001JD000533, 2002.

Rex, M., Salawitch, R. J., Gathen, P. v. d., Harris, N. R. P., Chipperfield, M. P., and Naujokat, B.: Arctic ozone loss and climate change, Geophys. Res. Lett., 31, L04116, doi:10.1029/2003GL018844, 2004.

Rosen, J. M.: The boiling point of stratospheric aerosols (Stratospheric aerosol boiling point measurement with photoelectric particle counter, observing sulfate radical as major constituent), J. Appl. Meteorol., 10, 1044-1046, 1971.

Santee, M. L., Lambert, A., Read, W. G., Livesey, N. J., Cofield, R. E., Cuddy, D. T., Daffer, W. H., Drouin, B. J., Froidevaux, L., Fuller, R. A., Jarnot, R. F., Knosp, B. W., Manney, G. L., Perun, V. S., Snyder, W. V., Stek, P. C., Thurstans, R. P., Wagner, P. A., Waters, J. W., Muscari, G., de Zafra, R. L., Dibb, J. E., Fahey, D. W., Popp, P. J., Marcy, T. P., Jucks, K. W., Toon, G. C., Stachnik, R. A., Bernath, P. F., Boone, C. D., Walker, K. A., Urban, J., and Murtagh, D.: Validation of the Aura Microwave Limb Sounder $\mathrm{HNO}_{3}$ measurements, J. Geophys. Res., 112, D24S40, doi:10.1029/2007JD008721, 2007.

Schreiner, W., Rocken, C., Sokolovskiy, S., Syndergaard, S., and Hunt, D.: Estimates of the precision of GPS radio occultations from the COSMIC/FORMOSAT-3 mission, Geophys. Res. Lett., 34, L04808, doi:10.1029/2006GL027557, 2007.

Shepherd, M. G. and Tsuda, T.: Large-scale planetary disturbances in stratospheric temperature at high-latitudes in the southern summer hemisphere, Atmos. Chem. Phys., 8, 7557-7570, doi:10.5194/acp-8-7557-2008, 2008.

Shibata, T., Sato, K., Kobayashi, H., Yabuki, M., and Shiobara, M.: Antarctic polar stratospheric clouds under temperature perturbation by nonorographic inertia gravity waves observed by micropulse lidar at Syowa Station, J. Geophys. Res., 108, 4105, doi:10.1029/2002JD002713, 2003.

Solomon, S.: Stratospheric Ozone Depletion: A Review of Concepts and History, Rev. Geophys., 37, 275-316, 1999.

Tabazadeh, A., Toon, O. B., and Jensen, E. J.: Formation and implications of ice particle nucleation in the stratosphere, Geophys. Res. Lett., 24, 2007-2010, doi:10.1029/97GL01883, 1997. 
Tabazadeh, A., Jensen, E. J., Toon, O. B., Drdla, K., and Schoeberl, M. R.: Role of the stratospheric polar freezing belt in denitrification, Science, 291, 2591-2594, doi:10.1126/science.1057228, 2001.

Teitelbaum, H. and Sadourny, R.: The role of planetary waves in the formation of polar stratospheric clouds, Tellus A, 50, 302-312, doi:10.1034/j.1600-0870.1998.t01-2-00004.x, 1998.

Teitelbaum, H., Moustaoui, M., and Fromm, M.: Exploring polar stratospheric cloud and ozone minihole formation: The primary importance of synoptic-scale flow perturbations, J. Geophys. Res., 106, 28173-28188, doi:10.1029/2000JD000065, 2001.
Wang, Z., Stephens, G., Deshler, T., Trepte, C., Parish, T., Vane, D., Winker, D., Liu, D., and Adhikari, L.: Association of Antarctic polar stratospheric cloud formation on tropospheric cloud systems, Geophys. Res. Lett., 35, L13806, doi:10.1029/2008g1034209, 2008.

Yoshiki, M., Kizu, N., and Sato, K.: Energy enhancements of gravity waves in the Antarctic lower stratosphere associated with variations in the polar vortex and tropospheric disturbances, J. Geophys. Res., 109, D23104, doi:10.1029/2004JD004870, 2004. 